\title{
Investigation of Ester- and Amide-Linker-Based Porous Organic Polymers for Carbon Dioxide Capture and Separation at Wide Temperatures and Pressures
}

Ruh Ullah, ${ }^{\dagger, \#}$ Mert Atilhan, ${ }^{*}{ }^{\dagger}$ Baraa Anaya, ${ }^{\dagger}$ Shaheen Al-Muhtaseb, ${ }^{\dagger}$ Santiago Aparicio, ${ }^{\ddagger}$ Hasmukh Patel, ${ }^{\S}, \#$ Damien Thirion," and Cafer T. Yavuz ${ }^{*, \|, \perp}$

${ }^{\dagger}$ Department of Chemical Engineering, Qatar University, PO Box 2713, Doha, Qatar

${ }^{*}$ Department of Chemistry, University of Burgos, 09001 Burgos, Spain

${ }^{\S}$ Department of Chemistry, Northwestern University, Evanston, Illinois 60208, United States

"Graduate School of EEWS, KAIST, 373-1 Guseong Dong, Yuseong Gu, Daejeon 305-701, Republic of Korea

${ }^{\perp}$ Department of Chemistry, KAIST, 373-1 Guseong Dong, Yuseong Gu, Daejeon 305-701, Republic of Korea

Supporting Information

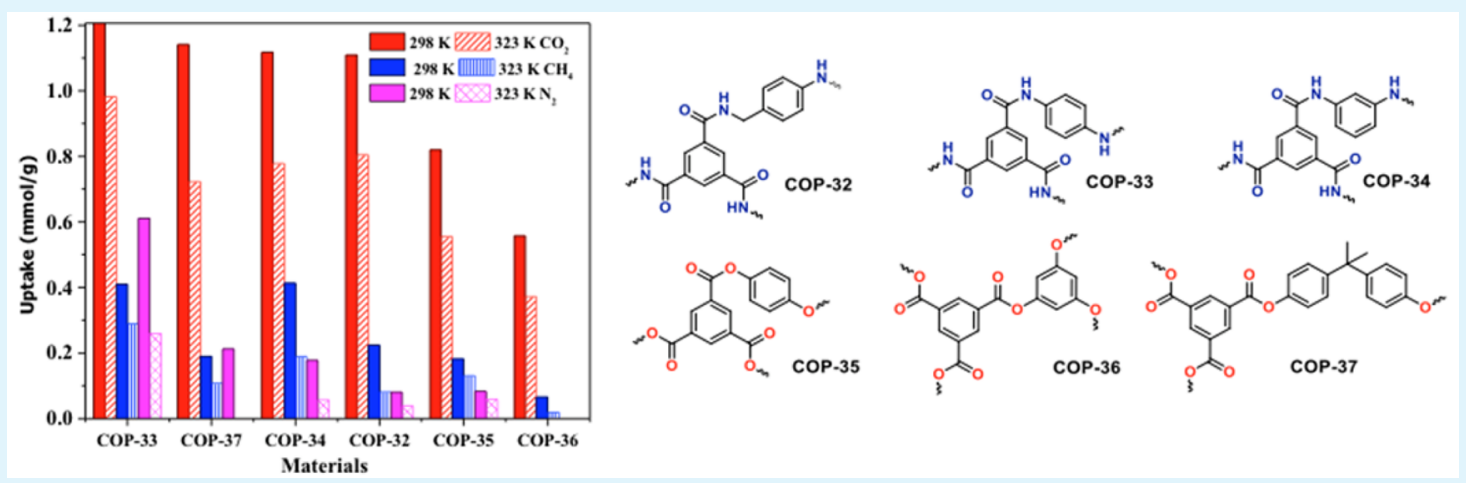

ABSTRACT: Organic compounds, such as covalent organic framework, metal-organic frameworks, and covalent organic polymers have been under investigation to replace the well-known amine-based solvent sorption technology of $\mathrm{CO}_{2}$ and introduce the most efficient and economical material for $\mathrm{CO}_{2}$ capture and storage. Various organic polymers having different function groups have been under investigation both for low and high pressure $\mathrm{CO}_{2}$ capture. However, search for a promising material to overcome the issues of lower selectivity, less capturing capacity, lower mass transfer coefficient and instability in materials performance at high pressure and various temperatures is still ongoing process. Herein, we report synthesis of six covalent organic polymers (COPs) and their $\mathrm{CO}_{2}, \mathrm{~N}_{2}$, and $\mathrm{CH}_{4}$ adsorption performances at low and high pressures up to 200 bar. All the presented COPs materials were characterized by using elemental analysis method, Fourier transform infrared spectroscopy (FTIR) and solid state nuclear magnetic resonance (NMR) spectroscopy techniques. Physical properties of the materials such as surface areas, pore volume and pore size were determined through BET analysis at $77 \mathrm{~K}$. All the materials were tested for $\mathrm{CO}_{2}, \mathrm{CH}_{4}$, and $\mathrm{N}_{2}$ adsorption using state of the art equipment, magnetic suspension balance (MSB). Results indicated that, amide based material i.e. COP-33 has the largest pore volume of $0.2 \mathrm{~cm}^{2} / \mathrm{g}$ which can capture up to the maximum of 1.44 $\mathrm{mmol} / \mathrm{g} \mathrm{CO}_{2}$ at room temperature and at pressure of 10 bar. However, at higher pressure of 200 bar and $308 \mathrm{~K}$ ester-based compound, that is, COP-35 adsorb as large as $144 \mathrm{mmol} / \mathrm{g}$, which is the largest gas capturing capacity of any COPs material obtained so far. Importantly, single gas measurement based selectivity of COP-33 was comparatively better than all other COPs materials at all condition. Nevertheless, overall performance of COP-35 rate of adsorption and heat of adsorption has indicated that this material can be considered for further exploration as efficient and cheaply available solid sorbent material for $\mathrm{CO}_{2}$ capture and separation.

KEYWORDS: $\mathrm{CO}_{2}$ capture, porous adsorbents, covalent organic polymers, high-pressure capture

\section{INTRODUCTION}

Sustainable and economical capture and separation of $\mathrm{CO}_{2}$ from fossil fuel based industries is highly desirable to govern the excessive emission, mitigate the adverse anthropogenic effects and uphold the overall concentration of greenhouse gases up to
Received: May 18, 2016

Accepted: July 26, 2016

Published: July 26, 2016 
the UN recommended level. ${ }^{1}$ In addition to the customarily used aqueous monoethanolamine systems, various other technologies and materials particularly solid sorbents ${ }^{2}$ such as metal organic framework (MOF), covalent organic framework (COF), ${ }^{3}$ activated carbon, mesoporous silicas, zeolites polybenzimidazole, inorganic materials, and many polymers ${ }^{4}$ have been explored to overcome the issues of capturing capacity, reusability, selectivity and stability of the sorbents materials. Among various solid materials, organic polymers have the additional benefits of simple preparation, low manufacturing cost, abundant availability, nontoxicity, biodegradability and structure flexibility for capturing different gases at different environmental conditions. Importantly, selection of the core monomers and linkers independently steer the physical properties as well as the structures of polymer networks. Literature in this field has the opinion that capturing route is mainly based on the physical sorption of the polymer materials which makes the process appropriate as long as the repeated useability of the solid sorbent is concern. This is still under debate in literature ${ }^{2,5}$ that gas uptake capacity of solid sorbents apparently dependent on the physical parameters like surface area, pore volume and structure rigidity of the materials. On the other hand physical properties which steer the gas capturing capacity are hooked to the selection of core monomers and linkers in case of polymer networks. Various organic polymeric materials prepared from the same building block, but, linked by different chain linkers have significant differences in the nature of physical parameters. ${ }^{6}$ For example microporous organic polymers (MOPs) prepared with benzene as core monomers and linked by two different agents 1,3,5-tris(bromomethyl)2,4,6-trimethylbenzene and 1,3,5-tris(bromomethyl)benzene have different surface areas $\left(609\right.$ and $\left.688 \mathrm{~m}^{2} / \mathrm{g}\right)$, pore volumes $\left(0.35\right.$ and $0.40 \mathrm{~cm}^{3} / \mathrm{g}$ ), and different $\mathrm{CO}_{2}$ adsorptions of 63.6 and $101 \mathrm{mg} / \mathrm{g}$, respectively. ${ }^{7}$ Covalent organic polymers (COPs) have been recently introduced as a new class of polymers compounds which have promising high $\mathrm{CO}_{2}$ capturing capacity ${ }^{8}$ mainly associated with the physical parameters of the materials. Cyanuric chloride based covalent organic polymers linked by piperazine and 4,4-bipiperidine have different surface areas of 168 and $158 \mathrm{~m}^{2} / \mathrm{g}$ respectively, which consequently have significant effect on the adsorption capacity. ${ }^{9}$ Liebl et al. ${ }^{10}$ have reported that $\mathrm{CO}_{2}$ capturing capacity of triazine-based porous polyimide (TPI) materials is mainly attributed to the combined effect of functionality of the surfaces and surface area of the network which can be tuned with the help of different linkers. It was further argued that the inflexible nature of the linkers at the center of materials in case of PTI-1 and PTI-2 as compared to the other polymer networks make the structures of these materials more rigid because of the covalent bonds ${ }^{11}$ incorporated by the linkers. Beside the larger surface area and pore volume; physical sorbents materials should have attractive outer surface and inner pore surfaces to capture $\mathrm{CO}_{2}$ from the stream of the flue gases. $\mathrm{CO}_{2}$ affinity toward the attaching site can be established by enhancing the basicity and functionalization ${ }^{12}$ of the capturing compounds. Sekiskardes et al. ${ }^{13}$ have attempted to introduce the nitrogen functionality (basicity) in various types of polymers by incorporating imidazole ring as a linker within the structure of polymers, however, materials with the largest surface area has shown excellent performance as long as the capture capacity of the sorbent is concern. So far most of the related research has been focused on the investigation of capturing capacity and selectivity of organic polymers, however, minor attention has been made toward the rate of the adsorption process. In our knowledge and as per the literature survey excluding porous polymers only few lithium based composite materials ${ }^{14}$ have been explored for the adsorption rate of $\mathrm{CO}_{2}$. Kato et al. ${ }^{15}$ has found that $\mathrm{Li}_{4} \mathrm{SiO}_{4}$ has the highest adsorption rate for $\mathrm{CO}_{2}$, which could capture up to $50 \mathrm{mg} / \mathrm{g} /$ min at $500{ }^{\circ} \mathrm{C}$ using TGA analysis techniques. It might be possible that a sorbent can have larger capturing capacity as compared to other counterparts, however, due to slow adsorption kinetics, despite lower capture capacity other counterpart materials might be faster in adsorption process and could be advantageous in processes that requires rapid gas adsorption-desorption cycles. Adsorption-desorption kinetics has similar importance as the capacity of the materials, since; rapid removal ${ }^{16}$ of the unwanted gas molecules is highly essential in some industrial processes ${ }^{17}$ to avoid further chemical reaction and formation of toxic hazardous compounds. Here in it has been attempted to investigate the effect of nitrogen ${ }^{18}$ and hydroxyl functionalities ${ }^{19}$ independently on the $\mathrm{CO}_{2}, \mathrm{~N}_{2}$, and $\mathrm{CH}_{4}$ adsorption capacity and rate of adsorption by making two different sets i.e. amide ${ }^{10,20}$ and ester based $^{11,21}$ COPs materials with two different core monomers and six different linkers. The objective of this work is to investigate the newly synthesized covalent organic polymers and their gas uptake performances considering various gases including $\mathrm{CO}_{2}, \mathrm{~N}_{2}, \mathrm{CH}_{4}$, and $\mathrm{H}_{2}$.

\section{EXPERIMENTAL SECTION}

Materials and Methodology. N,N-Diisopropylethylamine, 1,3,5benzene tricarbonyltrichloride, 4-aminobenzylamine, 1,4-phenylenediamine, 1,3-phenylenediamine, hydroquinone, phloroglucinol, bisphenol A were purchased from Sigma-Aldrich, and were used as received, however, dioxane, and ethanol were obtained from TCI, Japan.

In a typical synthesis (detailed experimental procedure given Supporting Information), N,N-diisopropylethylamine was added to linker (4-aminobenzylamine, 1,4-phenylenediamine, 1,3-phenylenediamine, hydroquinone, phloroglucinol, or bisphenol A) dissolved in 1,4 dioxane at room temperature. The dioxane solution of core $(1,3,5-$ benzene tricarbonyltrichloride) was added dropwise to the above solutions with continuous stirring at $12-14{ }^{\circ} \mathrm{C}$ in the atmospheric condition. Once the addition was finished, the reaction mixture slowly heated up to room temperature and it was stirred for $24 \mathrm{~h}$. The precipitate was washed with dioxane and soaked in ethyl alcohol three times over the period of $12 \mathrm{~h}$. The obtained product, COPs-32-37, was dried at room temperature under vacuum for $2 \mathrm{~h}$ and subsequently was dried at $110{ }^{\circ} \mathrm{C}$ in vacuum for $5 \mathrm{~h}$. Yield of the materials was measured to be in the range of $74-86 \%$.

Elemental analysis was performed at Korea Advance Institute of Science and Technology (KAIST) Central Research Instrument Facility using Thermo Scientific FLASH 2000 equipped with a TCD detector and Bruker Advance $400 \mathrm{MHz}$ WB equipped with a $4 \mathrm{~mm}$ probe. Solid-state $13 \mathrm{C}$ and $31 \mathrm{P}$ cross-polarization magic angle spinning NMR (CP-MAS) were conducted by spinning the samples at $12 \mathrm{kHz}$ and $20 \mathrm{kHz}$ respectively with the contact time of $5 \mathrm{~ms}$ and a delay time of $3 \mathrm{~s}$. Fourier transform infrared spectra (FTIR) were recorded on a Shimadzu IR-Tracer-100 equipped with a Gladi ATR module. Morphological study of materials was conducted with scanning electron microscope (FE-SEM-Nova Nano-450, Netherland) where the samples were uniformly and directly coated on an aluminum stub having $3 \mathrm{~nm}$ platinum coating, which was used as a conducting material. Physical properties of polymers were determined with nitrogen adsorption isotherms using a Micrometrics 3FLEX accelerated surface area and porosimetry analyzer at $77 \mathrm{~K}$. Prior to sorption measurement for physical parameters analysis, samples were activated through a degassing step at $423 \mathrm{~K}$ for $5 \mathrm{~h}$ under vacuum, which was applied by a mechanical roughing pump, manufactured by Varian Inc. The specific surface areas were derived from Brunauer- 
<smiles>CNC(=O)c1cc(C(=O)NC)cc(C(=O)NCc2ccc(NC)cc2)c1</smiles><smiles>CNC(=O)c1cc(C(=O)NC)cc(C(=O)Nc2ccc(NC)cc2)c1</smiles><smiles>CNC(=O)c1cc(C(=O)NC)cc(C(=O)Nc2cccc(NC)c2)c1</smiles><smiles>COC(=O)c1cc(C(=O)OC)cc(C(=O)Oc2ccc(OC)cc2)c1</smiles><smiles>COC(=O)c1cc(OC)cc(OC(=O)c2cc(OC)cc(C(=O)OC)c2)c1</smiles><smiles>COC(=O)c1cc(C(=O)OC)cc(C(=O)Oc2ccc(C(C)(C)c3ccc(OC)cc3)cc2)c1</smiles>

Figure 1. Repeating unit structure of amide and ester-linked covalent organic polymers (COPs-32-37).

Emmett-Teller (BET) method. Pore volume and pore diameter were determined via the BJH desorption model. FE-SEM (field emission scanning electron microscope) was taken using Nova 230 to study the structure of materials. Tapping density of the materials is measured with the help of AUTOTAP density analyzer from Quantachrome Instruments at the tapping rate of 2000 per hour. Prior to density measurement samples were dried in oven at $110{ }^{\circ} \mathrm{C}$ for $24 \mathrm{~h}$ to evacuate the materials from water content.

Thermal stability was studied with PerkinElmer Pyris 6 (Thermogravimetric Analysis) TGA machine, where materials were heated in $\mathrm{N}_{2}$ environment from 30 to $800{ }^{\circ} \mathrm{C}$ at the rate of $3{ }^{\circ} \mathrm{C}$ per minute. On the other hand, in situ infrared Fourier transform spectroscopy (FTIR) was used to investigate the interaction of $\mathrm{CO}_{2}$ with COP material through the in situ diffuse reflectance (DRIFTS) measurements techniques. Certain amounts of COPs materials were mixed with potassium bromide powder in a proper ratio to dilute the magnitude of materials under investigation. The solid mixture was then, degassed for at least $12 \mathrm{~h}$ using BET analysis system prior to in situ measurement. Diluted COP material was subjected to various pressures ( 0.1 to 1 bar) ranges at $25^{\circ} \mathrm{C}$ and data was collected for each pressure range. Pressure was applied manually, into the closed chamber containing diluted COPs materials. Spectra of COP material exposed to different pressures of $\mathrm{CO}_{2}$ were collected after allowing at least $5 \mathrm{~min}$ for adsorption saturation. Background spectrum obtained with pure $\mathrm{KBr}$ detector in $\mathrm{CO}_{2}$ environment was subtracted from the diluted samples spectrum to eliminate the contribution of $\mathrm{CO}_{2}$ in the bulk.

Magnetic suspension balance (MSB) from Rubotherm Prazisions Messtechnik GmbH equipped with automated Teledyne Isco $260 \mathrm{D}$ pump was used to measure the low and high pressure gas uptake of the synthesized sorbent materials and this apparatus is located at Qatar University laboratory. Details about experimental set up of MSB for high pressure gases measurement has been mentioned in literature previously. ${ }^{22}$ However, in a typical procedure, fixed amount $(0.10-0.2$ g) of each sample was first evacuated for at least $12 \mathrm{~h}$ at $101{ }^{\circ} \mathrm{C}$ within the closed sample chamber of balance to completely eliminate the effect of humidity. Four gas cylinders high purity (grade-2) gas cylinders are connected to gas dosing system (GDS) via external pump to pressurize the required gas into the measuring cell. The maximum set pressure (10 for low pressure measurements and 200 bar for high pressure measurements) was applied stepwise by increasing the pressure gradually from 1 bar up to the maximum of 10 and 200 bar, respectively. Each pressure point took about $60 \mathrm{~min}$ to gain the set point of pressure and temperature equilibrium, recorded four different sets of measurements and collected the data points. In case of low pressure measurement each measurement point was taken after $1 \mathrm{bar}$ increment reaching up to the maximum of $10 \mathrm{bar}$, totalling of 12 measurements including evacuation step of the cell at the beginning and at the final stage of the measurement cycle. For high-pressure measurement, data was collected by total of 21 measurement points including initial and final evacuation. Initially, pressure of the system was increased gradually from $5,10,15$, and 25 bar with each step of $1 \mathrm{~h}$ and then each point was incremented with 25 bar reaching to 200 bar. After reaching the maximum set pressure points both in low and high pressure condition, pressure of the system was gradually reduced exactly with the same measurement points starting from the high pressure and reaching to the last evacuation point to complete the desorption process. The system is fully automated and the pressure goes to next higher point after completing the previous measurement point. The system was brought to atmospheric pressure subsequently by final evacuation of at least $5 \mathrm{~h}$ at the same temperature. The above procedure was repeated with the same sample (unchanged sample) each for three temperatures, that is, 308, 323, and $338 \mathrm{~K}$ and three gases $\left(\mathrm{CO}_{2}, \mathrm{~N}_{2}\right.$, and $\left.\mathrm{CH}_{4}\right)$ with total evacuation of at least $10 \mathrm{~h}$ in each case. COPs samples were exposed to cyclic (at least 3 cycles per samples) adsorption/desorption experiments for observing the activity and performance of the materials.

Moreover, MSB apparatus is equipped with in situ density measurement capability and it is used for obtaining the density values for the gases that are processed in the experimental measurement cell during the adsorption measurements. To make sure the physical state of the measured gas and rule out possible condensation of the gases on the pores of the adsorbent material, the density of the gas is experimented in the MSB. Then this density data is crosschecked by using a NIST reference database for pure components via REFPROP 9.1 software. ${ }^{23}$ Last but not least, the density data that is obtained from in situ measurements in the MSB and the calculated density values at high pressures by using REFPROP software is compared with published material for the pure gases that are used in this work and no ambiguity has been observed for the gas densities. ${ }^{24}$

\section{RESULTS AND DISCUSSIONS}

Figure 1, shows the schematics of amide and ester linked covalent organic polymers obtained with the procedure mentioned in the Materials and Methodology section. Organic polymers with two different (i.e., $\mathrm{OH}$ and $\mathrm{N}$ ) functionalities were prepared with the objective to examine the effectiveness of two functionalities for large capacity and high selectivity $\mathrm{CO}_{2}$ capture at various temperatures and pressures. Amides are proven to have high polarity while ester have good stability and therefore may have applications in high pressure $\mathrm{CO}_{2}$ adsorption. ${ }^{25}$ Thus, as shown in the schematic fundamental block, benzene tricarbonyltrichloride was linked by two different linkers, having nitrogen (amide) (COP-32, COP-33, and COP-34) and hydroxyl (ester) ions (COP-35, COP-36, and COP-37) functionality with in the repeating chain structures. COPs that are presented in this work are numbered in a consecutive way according previous publications. ${ }^{9,26}$

Elemental analysis of COPs materials (given in Table 1) shows the experimental percentage contents of carbon, 
Table 1. Elemental Analysis of COPs-32-37

\begin{tabular}{ccccr} 
material ID & $\mathrm{C} \%$ & $\mathrm{H} \%$ & $\mathrm{~N} \%$ & $\mathrm{O} \%$ \\
COP-32 & 68.9 & 5.3 & 12 & 1.6 \\
COP-33 & 67.4 & 5 & 13.8 & 1.6 \\
COP-34 & 59.8 & 4.8 & 27.8 & 1.6 \\
COP-35 & 66.1 & 3.6 & & 29.9 \\
COP-36 & 61.2 & 3.9 & & 34.8 \\
COP-37 & 75.8 & 5.4 & & 19.5 \\
\hline
\end{tabular}

hydrogen, nitrogen, and oxygen in these structures. Table 1 reveals that amides based polymers (COP-32, COP-33, and COP-34) have same concentration of $\mathrm{O}(1.6 \%)$, but carbon content is reducing from $68.9 \%$ to $59.8 \%$ as the concentration of $\mathrm{N}$ increases from $12 \%$ to $27.8 \%$ indicating strong interaction of linkers with parent monomer. The high content of nitrogen in COP-34 indicates that 1,3-phenylene is more reactive than 4aminobenzylamine and 1,4-phenylene with tricarbonyltrichloride resulting in chain structures of COP-34. On the hand, ester linked polymers (COP-35, COP-36, and COP-37) have obviously more oxygen concentration than the amide type materials owing to the presence of hydroxyl moiety in the linkers molecules. Additionally, COP-37 has the highest concentration of carbon (75.8\%) among all new materials with the least oxygen quantity (19.5) among the ester type chained covalent organic polymers. It is important to note that, COP-33 in amide series and COP-35 in ester series have the average carbon concentration of $67.4 \%$ and $66.1 \%$ respectively, with average content of nitrogen (13.8\%) and oxygen (29.9\%). Additionally, FTIR analysis (Figure 1, Supporting Information) confirmed formation of amides and ester based materials, since prominent peaks at $1530-1660,1735$, and $1220 \mathrm{~cm}^{-1}$ observed, which can be associated with $\mathrm{N}-\mathrm{H}$ bending, $\mathrm{C}=$ $\mathrm{O}$, and $\mathrm{C}-\mathrm{O}$ stretching, respectively. ${ }^{27}$ The two major peaks in the range of 1735 and $1300-1000 \mathrm{~cm}^{-1}$ indicates the presence of saturated aliphatic ester and carbonyl group. ${ }^{28}$ The three prominent peaks in the range of 3400, 1615 , and $1516 \mathrm{~cm}^{-1}$ in COP-32, COP-33, and COP-34 are attributed to the presence of the amino group, $\mathrm{N}-\mathrm{H}$ stretching, and $\mathrm{N}-\mathrm{O}$ stretching mode indicating formation of the required amide based materials. $^{29}$

Thermal stability of the materials were tested by sintering materials in nitrogen environment at the rate of $5{ }^{\circ} \mathrm{C} / \mathrm{min}$ using TGA equipment. As shown in Figure 2, only 4\% degradation was observed in all of the material up to $250{ }^{\circ} \mathrm{C}$, whereas $3 \%$ weight loss can be seen up to $100{ }^{\circ} \mathrm{C}$, which is mainly associated with the desorbed water in the porous structures of materials. As shown in the inlet of Figure 2, further 1\% weight loss from 100 to $250{ }^{\circ} \mathrm{C}$ can be attributed to the removal of some unreacted organic compounds and resins. The most common feature in all of the materials was the rapid weight loss started in the range of $350-400{ }^{\circ} \mathrm{C}$. This third weight loss step can associated with the actual decomposition of covalent organic polymers, since almost $60 \%$ of the materials were degraded in the temperature range of $300-600{ }^{\circ} \mathrm{C}$. This clearly indicates that, these compounds have good thermal stability and can be used at temperature as high as $250{ }^{\circ} \mathrm{C}$. Mason et al, related the initial $7 \%$ weight loss to the removal of $\mathrm{NH}_{2}$ group in amine modified polymer of intrinsic microporosity (PIMs) however, the covalent organic polymer presented in this article possess the intrinsic functionality without any further amine impregnation, thus, these materials have shown higher thermal stability than PIM. ${ }^{30}$ COPs (COP-H, COP-C) reported by Sun et al. and modified with palladium nanoparticles decomposed up to $60 \%$ at around $250{ }^{\circ} \mathrm{C}$, indicating thermal in-stability ${ }^{31}$ as compared to our COPs materials which have shown structure strengthens under similar condition. This higher thermal stability of COPs (COP-32-37) materials can be mainly associated with the strong hydrogen bonding between building block monomers and different linkers. ${ }^{32}$

Additionally, three connecting nodes of building block monomer, that is, tricarbonyl trichloride can be easily chained by two connecting nodes linkers, which ensure rigidity of the materials and therefore, retain the porous structure stability at temperature as high as $300{ }^{\circ} \mathrm{C} .{ }^{33}$ Importantly, thermal stability of polymers can be further extended by conjugating surface $\mathrm{OH}$ ion with 3,4-diace-toxycinnamic acid (DACA), however, this will hinder $\mathrm{CO}_{2}$ adsorption. ${ }^{34}$ Figure 3 shows the SEM micrographs of all COPs materials with the same scale of

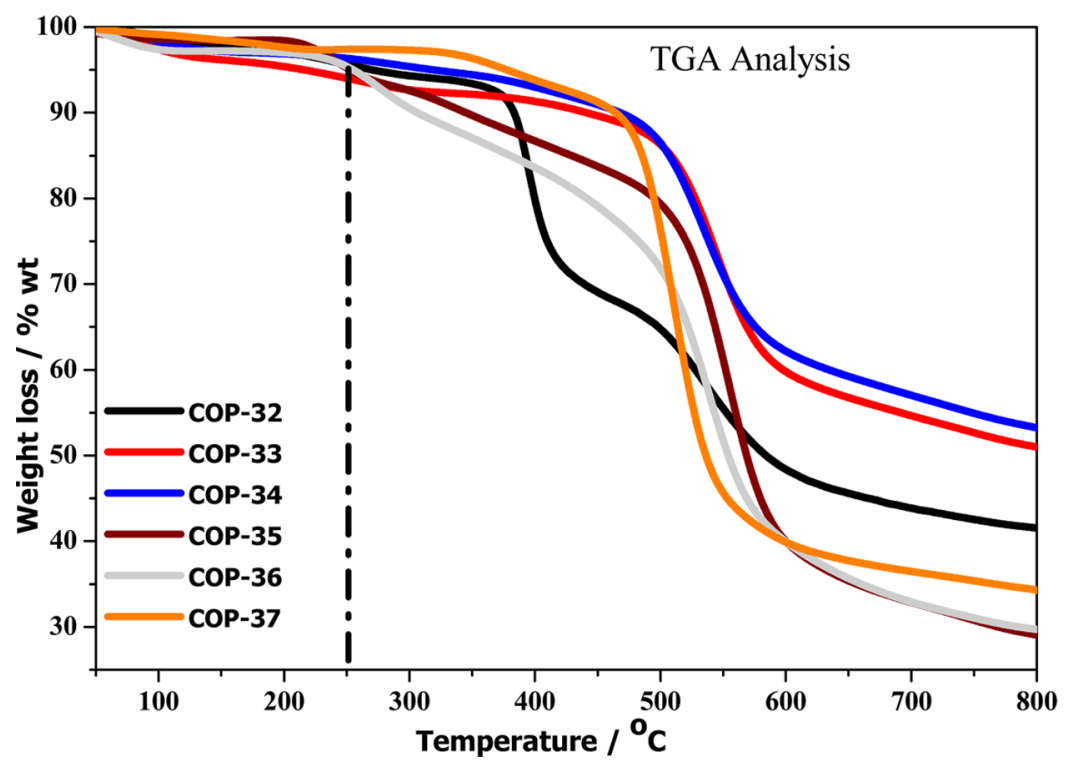

Figure 2. Thermal degradation profile of COPs-32-37 up to $800{ }^{\circ} \mathrm{C}$, performed at $5{ }^{\circ} \mathrm{C} / \mathrm{min}$ in $\mathrm{N}_{2}$ atmosphere. 

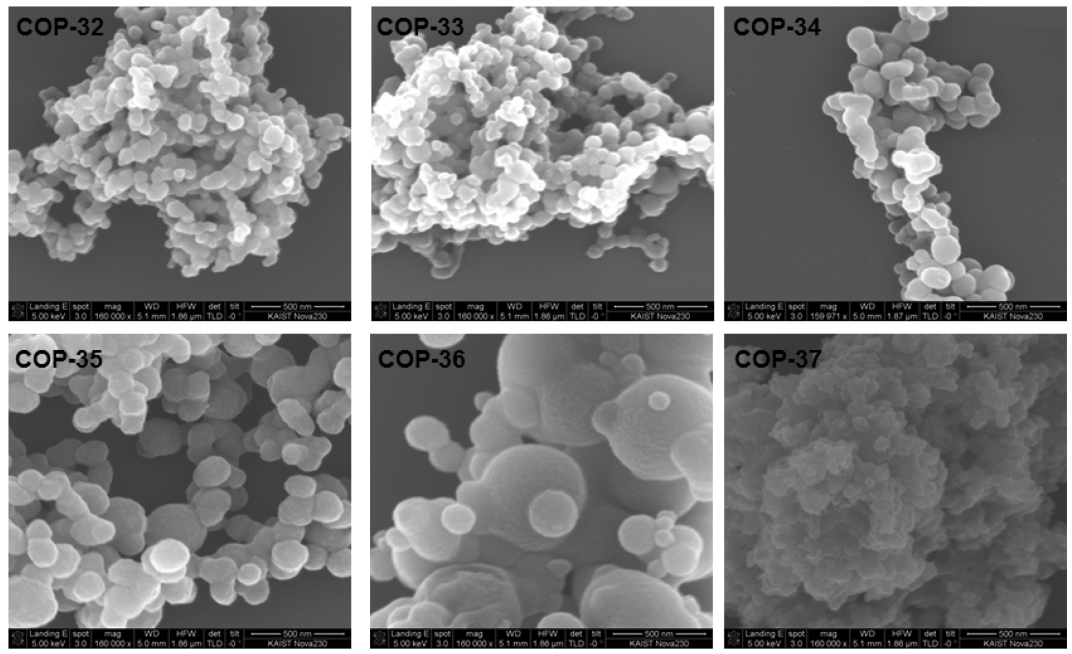

Figure 3. Morphology of COPs-32-37 obtained from FE-SEM (bar scale $=500 \mu \mathrm{m}$ ).

magnification $(\times 100000)$. It can be seen from the SEM images that COP-32-34 are in the form of agglomeration and have almost similar structures and sizes. In case of COP-32 and COP-33 very small sizes particles aggregated to form bunch like structures with negligible porosity, however, in case of COP-34 small sizes particles made elongated structures indicating formation of chain polymers.

On the other hand ester linker based COPs (COP-35-36) except for COP-37 have almost bigger size agglomerates with different sizes from very small to very large spherical like assemblies. SEM images further reveal that COP-37 has very small particle size as compared to other counterpart where the material makes a plum like shape. Although COP-35 has different sizes particulate, however, the overall size of this material is smaller than COP-36 but, larger than COP-37. Since, single building block monomer, that is, tricarbonyl trichloride has been used for the synthesis of these materials, however, variation in the aggregation of particles to form agglomerated structure can be attributed to the differences in the connecting sites of various linkers.

Along with functionality ${ }^{35}$ and selectivity, pore volume and surface area also play crucial role ${ }^{36}$ in adsorption-desorption performance of solid sorbents to capture large quantity of flue gases. ${ }^{37}$ Physical parameters, such as pore volume, surface area, pore volume distribution and pore size of COPs materials were investigated through liquid nitrogen adsorption-desorption isotherms, as shown in figures given in Supporting Information (Figure S2). It is evident that $\mathrm{N}_{2}$ isotherms of all materials have type III characteristics indicating multilayer pore filling with weak interaction between adsorbate and adsorbent. ${ }^{38}$ Detail investigation of the pore size distribution (Figure S2), reveal that COP-32-COP-34 have both mesoporous and macro porous sizes pore diameters, while COP-35 and COP-36 are mostly mesoporous structures.

Table 2 shows the physical properties, that is, BET surface areas, pore volume, and density of COPs materials. Excluding COP-37, it can be seen that amide based polymers have generally greater surface area and larger pore volume than ester type materials. Among all the materials COP-35 has the lowest BET surface area of $5.4 \mathrm{~m}^{2} / \mathrm{g}$, whereas COP-37 has the largest BET surface are of $54.2 \mathrm{~m}^{2} / \mathrm{g}$. On the other hand COP-33 has the largest pore volume of $0.2 \mathrm{~cm}^{3} / \mathrm{g}$, with the second largest Langmuir surface area of $73.4 \mathrm{~m}^{2} / \mathrm{g}$, however, COP-36 has the
Table 2. BET Analysis and Physical Properties of COPs Materials

\begin{tabular}{|c|c|c|c|c|c|}
\hline \multirow[b]{2}{*}{ material } & \multicolumn{2}{|c|}{$\begin{array}{l}\text { material density } \\
\left(\mathrm{g} / \mathrm{cm}^{3}\right)\end{array}$} & \multicolumn{2}{|c|}{ surface area $\left(\mathrm{m}^{2} / \mathrm{g}\right)$} & \multirow[b]{2}{*}{ pore volume $\left(\mathrm{cm}^{3} / \mathrm{g}\right)$} \\
\hline & bulk & tapped & BET & Langmuir & \\
\hline COP-32 & 0.152 & 0.190 & 46.00 & 63.80 & 0.139 \\
\hline COP-33 & 0.122 & 0.156 & 53.20 & 73.40 & 0.200 \\
\hline COP-34 & 0.194 & 0.253 & 33.40 & 46.20 & 0.095 \\
\hline COP-35 & 0.086 & 0.125 & 5.40 & 7.50 & 0.110 \\
\hline COP-36 & 0.146 & 0.220 & 11.10 & 15.40 & 0.032 \\
\hline COP-37 & 0.135 & 0.200 & 54.20 & 75.00 & 0.190 \\
\hline
\end{tabular}

smallest pore volume among all COPs materials. The surface area and pore volume of these COPs materials (COP-32-37) are found to be much smaller than the other COPs materials (COP-1-4) which was measured to be $2015 \mathrm{~m}^{2} / \mathrm{g}$ and 1.76 $\mathrm{cm}^{3} / \mathrm{g}$. ${ }^{39}$ The lower surface area and smaller pore volumes of COP-32-37 than COPs materials prepared and they can be attributed to the differences in the aromatic rings of backbone monomers. ${ }^{39}$ COP-1-4 have been prepared with tris(4bromophenyl) benzene, which have 3 benzene rings in the building block monomers, while COP-32-37 have a single benzene ring in the building block monomer (benzene tricarbonyltrichloride). It can be assumed that the structures of COP-34-37, which have single benzene ring in the backbone may be more compact due to the attachment of large number of linkers' molecules. However, in case of COP-1 to COP-4 backbone monomers have three benzene rings and each ring is connected by linkers making a hexagonal like loop structures with more unoccupied free space within the molecules. ${ }^{39}$ The loop like molecular arrangements in COPs prepared previously elsewehere ${ }^{39,40}$ allows larger space within the structure as compared to the squeezed structures of COP$32-37$, which results in larger pore volume and larger surface area.

Adsorption capacity of COPs materials were first tested with BET apparatus for $\mathrm{CO}_{2}$ and $\mathrm{N}_{2}$ gases at standard temperature and pressure. Table 3 shows the overall performance of all the materials at low pressure of 1 bar and $298 \mathrm{~K}$, which reveals that COP-33 has the highest $\mathrm{CO}_{2}$ adsorption capacity, whereas COP-36 has the highest $\mathrm{N}_{2}$ adsorption capacity. Adsorption isotherms of $\mathrm{CO}_{2}$ and $\mathrm{N}_{2}$ at $298 \mathrm{~K}$ and 1 bar are given in 
Table 3. $\mathrm{CO}_{2}$ and $\mathrm{N}_{2}$ Adsorption Capacity and Selectivity at $298 \mathrm{~K}$ and 1 bar

\begin{tabular}{cccc} 
& \multicolumn{2}{c}{ uptake $(\mathrm{mmol} / \mathrm{g})$} & \\
\cline { 2 - 3 } COPs & $\mathrm{CO}_{2}$ & $\mathrm{~N}_{2}$ & selectivity $\mathrm{CO}_{2}: \mathrm{N}_{2}$ \\
COP-32 & 0.444 & 0.020 & $22: 1$ \\
COP-33 & 0.600 & 0.019 & $32: 1$ \\
COP-34 & 0.470 & 0.024 & $20: 1$ \\
COP-35 & 0.283 & 0.022 & $13: 1$ \\
COP-36 & 0.330 & 0.023 & $15: 1$ \\
COP-37 & 0.444 & 0.0175 & $25: 1$ \\
\hline
\end{tabular}

Supporting Information (Figure S3), which clearly demonstrate that COP-33 up takes $0.5963 \mathrm{mmol} / \mathrm{g} \mathrm{CO}_{2}$ which is the highest among all and more than twice the uptake by COP-35 (0.2831 $\mathrm{mmol} / \mathrm{g}$ ). Additionally, COP-33 has the best selectivity of 32:1 for $\mathrm{CO}_{2}: \mathrm{N}_{2}$ than all other materials, whereas COP-35 has the lowest overall performance as long as the adsorption capacity of materials is concern. When all materials are considered, better gas uptake performance of COP-33 among the other materials, particularly in comparison to COP-35 can mainly be attributed to the largest pore volume and high surface area. On the hand COP-35 has the smallest surface area among all materials, which makes this material less capable to adsorb $\mathrm{CO}_{2}$ at these pressure and temperature conditions.

All COP materials were further examined for adsorption of $\mathrm{CO}_{2}$ as well as $\mathrm{N}_{2}$ and $\mathrm{CH}_{4}$ at 10 bar and different temperatures. The adsorption desorption isotherms of $\mathrm{CO}_{2}$ at $10 \mathrm{bar}$ and two different temperatures, that is, 298 and $323 \mathrm{~K}$ are given in Figure 4, where Table 4 shows the complete experimental data, however, $\mathrm{N}_{2}$ and $\mathrm{CH}_{4}$ adsorption isotherms can be viewed in the Supporting Information. It is evident from Figure 4 that like ambient condition COP-33 adsorbed more $\mathrm{CO}_{2}$ than all other COPs materials at increased pressure of 10 bar and 298 and $323 \mathrm{~K}$. However, $\mathrm{CO}_{2}$ uptake of COP-33 was $1.44 \mathrm{mmol} / \mathrm{g}$ at $298 \mathrm{~K}$, which was reduced to $0.98 \mathrm{mmol} / \mathrm{g}$ at higher temperature of $323 \mathrm{~K}$, due to the exothermic characteristic of adsorption process. Figure 4, further reveals that amide based polymers COP-33, COP-32, and COP-34 generally up take more $\mathrm{CO}_{2}$ than ester based materials i.e. COP-35, COP-36, and COP-37 at same pressure and temperature conditions. It can be seen that $\mathrm{CO}_{2}$ uptake capacity of amide type polymers (COP-32, COP-33, and COP$34)$ vary according to the size of their pore volume and surface area. Since, trend in the $\mathrm{CO}_{2}$ adsorption capacity of amide based materials is COP-33 > COP-32 > COP-34, which is exactly similar to the pore volume $\left(0.2>0.139>0.095 \mathrm{~cm}^{3} / \mathrm{g}\right)$ and surface areas of these materials.

Similarly, effect of pore volume on the adsorption capacity of $\mathrm{CO}_{2}$ at lower pressure was also observed in ester-based materials, since the pore volume and adsorption capacity were vary as COP-37 > COP-35 > COP-36 which are given in Table 2 and 3. This effect of pore volume on $\mathrm{CO}_{2}$ uptake capacity is prominent at higher temperature of $323 \mathrm{~K}$ as compared to 298 K. Additionally, various researchers have correlated the adsorption capacity of materials with concentration of nitrogen functionality, however, in our case COP-34 up take lowest $\mathrm{CO}_{2}$ among the amide based polymers though it has the largest content of nitrogen. It can be deduced from these findings that at lower pressure (up to $10 \mathrm{bar}$ ), pore volume, and surface areas not the $\mathrm{N}$ content are the main drivers for high quantity $\mathrm{CO}_{2}$ adsorption in amide based covalent organic polymers. Xiang et al. ${ }^{39}$ also found similar effect of pore volume on the $\mathrm{CO}_{2}$ adsorption capacity in three covalent organic polymers (namely, COP-1, COP-2, COP-3) with the exception of COP-4, which showed highest surface area and was prepared from triazine and has $\mathrm{N}$ enriched structure. Upon comparing the physical parameters (such as surface area and pore volumes) and adsorption capacity of porous COP32-37 materials with literature, it can be seen that porous aromatic framework (PAF) ${ }^{41}$ having surface area as high as $5600 \mathrm{~m}^{2} / \mathrm{g}$ up takes $1300 \mathrm{mg} / \mathrm{g}$ (about $33 \mathrm{mmol} / \mathrm{g}$ ) at $48 \mathrm{bar}$ and $298 \mathrm{~K}$. Similarly, PPN-4 with surface area of $6610 \mathrm{~m}^{2} / \mathrm{g}$ and pore volume of $3.04 \mathrm{~cm}^{3} / \mathrm{g}$, adsorbs $50 \mathrm{mmol} / \mathrm{g} \mathrm{CO}_{2}$ at $50 \mathrm{bar}$ and $295 \mathrm{~K}^{42}$

Upon checking the adsorption capacity of these materials for $\mathrm{N}_{2}$ and $\mathrm{CH}_{4}$ it can be seen that COP-33 and COP-34 adsorb certain quantities of gases other than $\mathrm{CO}_{2}$ at pressure of $10 \mathrm{bar}$, however, all other materials are almost inert and do not uptake other $\mathrm{N}_{2}$ and $\mathrm{CH}_{4}$. As shown in Table 4 COP-33 adsorb comparatively more nitrogen and methane than all other materials, which are 0.61 and $0.41 \mathrm{mmol} / \mathrm{g}$ at $298 \mathrm{~K}$ and $10 \mathrm{bar}$. As a general analysis it can be assume that amide based COPs materials adsorb certain amount of $\mathrm{N}_{2}$ and $\mathrm{CH}_{4}$ along with $\mathrm{CO}_{2}$; however, ester-based materials are totally inactive for adsorption of $\mathrm{N}_{2}$ and $\mathrm{CH}_{4}$ at pressure up to 10 bar and temperatures of 298 and $323 \mathrm{~K}$.

Since, pore volume and surface areas of amide based COPs are higher than the ester based materials, preliminary, it can be assumed that these physical properties are responsible for adsorption of $\mathrm{N}_{2}$ and $\mathrm{CH}_{4}$ by amide type COPs materials. Additionally, selectivity of most of the ester-based polymers (COP-36, COP-37) is much higher than that of amides COPs
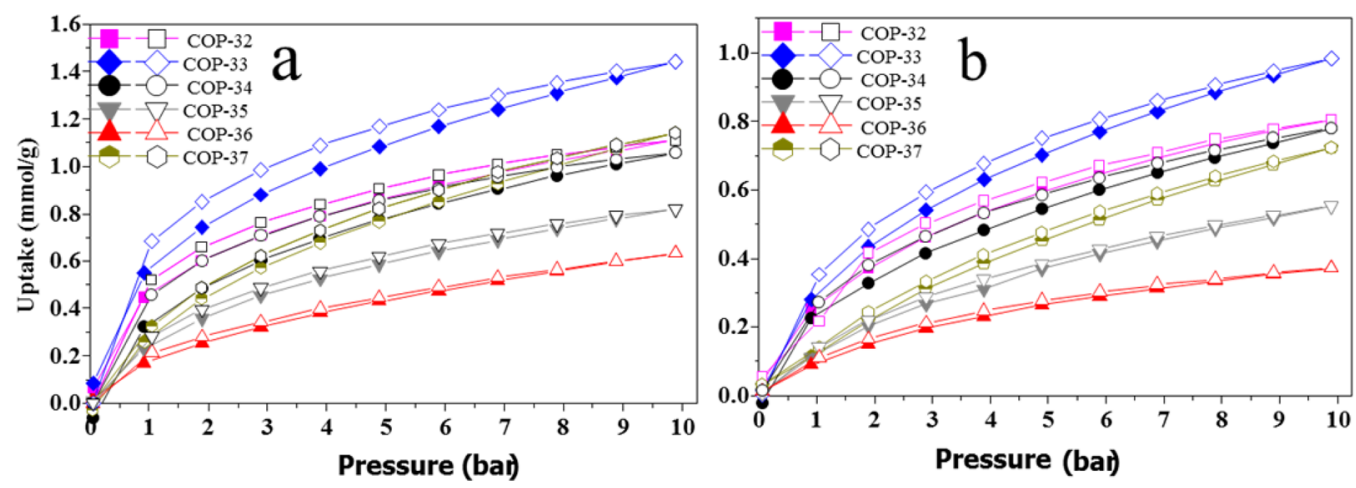

Figure 4. $\mathrm{CO}_{2}$ adsorption at (a) 298 and (b) $323 \mathrm{~K}$ and 10 bar. 
Table 4. Maximum Adsorption of $\mathrm{N}_{2}, \mathrm{CO}_{2}$, and $\mathrm{CH}_{4}$ by $\mathrm{COP}$ Materials at 10 bar

\begin{tabular}{|c|c|c|c|c|c|c|c|c|}
\hline \multirow[b]{3}{*}{ material } & \multicolumn{2}{|c|}{$\mathrm{CO}_{2}(\mathrm{mmol} / \mathrm{g})$} & \multicolumn{2}{|c|}{$\mathrm{CH}_{4}(\mathrm{mmol} / \mathrm{g})$} & \multicolumn{2}{|c|}{$\mathrm{N}_{2}(\mathrm{mmol} / \mathrm{g})$} & \multicolumn{2}{|c|}{ selectivity $\left(\mathrm{CO}_{2}: \mathrm{N}_{2}: \mathrm{CH}_{4}\right)$} \\
\hline & \multicolumn{8}{|c|}{ temperature } \\
\hline & $298 \mathrm{~K}$ & $323 \mathrm{~K}$ & $298 \mathrm{~K}$ & $323 \mathrm{~K}$ & $298 \mathrm{~K}$ & $323 \mathrm{~K}$ & $298 \mathrm{~K}$ & $323 \mathrm{~K}$ \\
\hline COP-32 & 1.11 & 0.80 & 0.22 & 0.08 & 0.08 & 0.04 & $14: 1: 3$ & $20: 1: 2$ \\
\hline COP-33 & 1.44 & 0.98 & 0.41 & 0.29 & 0.61 & 0.26 & $4: 1: 2$ & $4: 1: 1$ \\
\hline COP-34 & 1.12 & 0.78 & 0.41 & 0.19 & 0.18 & 0.06 & $6: 1: 2$ & $14: 1: 3$ \\
\hline COP-35 & 0.82 & 0.55 & 0.18 & 0.13 & 0.08 & 0.06 & $10: 1: 3$ & $9: 1: 2$ \\
\hline COP-36 & 0.56 & 0.37 & 0.07 & 0.02 & 0 & 0 & $\infty$ & $\infty$ \\
\hline COP-37 & 1.14 & 0.72 & 0.19 & 0.11 & 0.21 & 0 & $\infty$ & $\infty$ \\
\hline
\end{tabular}

(COP-32, COP-33, and COP-33). Among amide type COPs materials, COP-32 has better selectivity, than COP-33 and COP-34 at $323 \mathrm{~K}$ and 10 bar, however, selectivity of COP-33 is better than all other materials at $298 \mathrm{~K}$ and 10 bar. It must be noted that, COP-33 has also best selectivity among all other materials for $\mathrm{CO}_{2}$ over $\mathrm{N}_{2}$ at $298 \mathrm{~K}$ and 1 bar. Figure 5 reveals

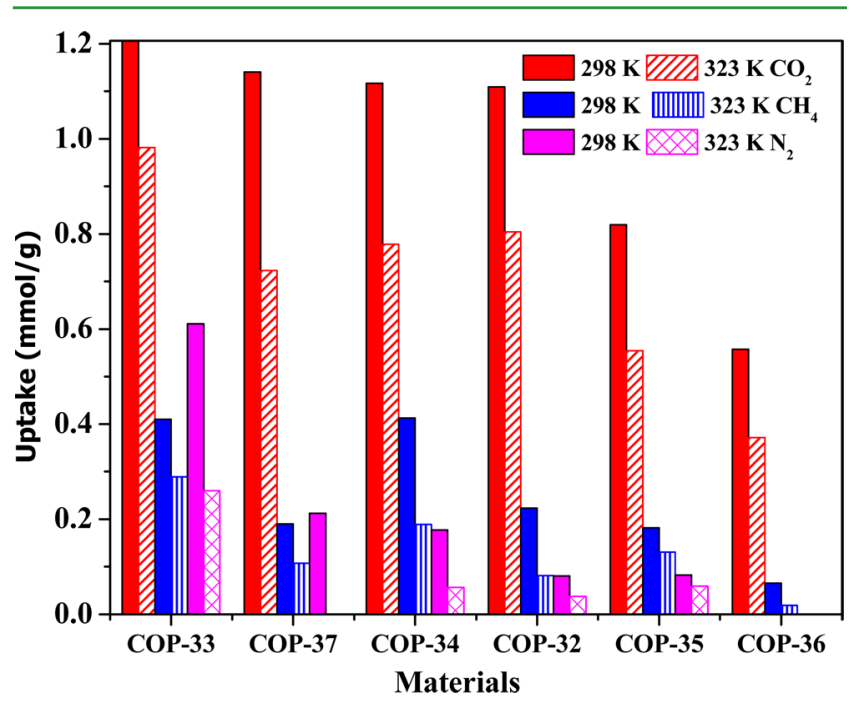

Figure 5. Overall performance of all COPs (32-37) materials showing maximum adsorbed capacity of $\mathrm{CO}_{2}, \mathrm{CH}_{4}$, and $\mathrm{N}_{2}$ at 10 bar and 298 and $323 \mathrm{~K}$.

that with the exception of small differences, COP-33, COP-37, COP-34, and COP-32 almost uptake similar $\mathrm{CO}_{2}$ adsorption quantity at 10 bar and room temperature, whereas, COP-35 and COP-36 adsorb lower amount of $\mathrm{CO}_{2}$ under similar condition. The lower $\mathrm{CO}_{2}$ adsorption at these pressure and temperature conditions by COP-35 and COP-36 can be associated with the lower pore volume and lower surface area as compared to other COPs materials presented in this article.

Precombustion such as in integrated gasification combine cycle system (IGCC) requires $\mathrm{CO}_{2}$ separation and capture and relatively high pressure and high temperature, thus COPs materials were also tested under high pressure and high temperature. ${ }^{43}$ Performance of all the materials at high pressure up to 200 bar for $\mathrm{CO}_{2}$ uptake is shown in Figure 6, where the isotherms were obtained at three different temperatures of 308 , 323 , and $338 \mathrm{~K}$. Detail investigation of adsorption/desorption isotherms reveal that behavior of adsorption before the critical pressure range $(70-80$ bar) is different than that above this pressure value. It is evident that at low pressure, that is, up to the maximum of 80 bar adsorption is gradually increasing with pressure similar to type III isotherms, which represents very weak adsorbate-adsorbent interaction unlike to type II and IV isotherms which have a knee in this range indicating monolayer formation. This particular behavior of the isotherms at this pressure range has been associated with the localized adsorption of $\mathrm{CO}_{2}$ molecules in the vicinity of the unfilled pores. ${ }^{44}$ Upon comparing the adsorption isotherms of COP materials in the present study to that of polymers of intrinsic microporosity (PIMs) investigated by Regno et al. ${ }^{45}$ it can be seen that unlike to our case, there is a sharp increase in the adsorption of $\mathrm{CO}_{2}$ at the lower pressure range which was mainly attributed to the microporosity of materials. However, in our case after the critical pressure range a sharp rise in the adsorption is observed with increase in pressure which is extended up to the pressure of 130 bar, whereas at further high pressure the $\mathrm{CO}_{2}$ up take was almost flat with pressure and the isotherms have very low slope in this region. Here, in we argue that at above critical pressure (around 71 bar), both pore fillings and enhancement in the interaction of adsorbateadsorbent commenced resulting in abrupt increase in the $\mathrm{CO}_{2}$ up take, which leads to the formation of type $\mathrm{V}$ isotherms without hysteresis.

As shown in Figure $6 \mathrm{CO}_{2}$ isotherms of all the materials have similar trend of large adsorption at low temperature, that is, the adsorption capacity varies with temperature as $308>323$ and $338 \mathrm{~K}$; however, in case of COP-37, the adsorption isotherms were a bit different at low pressure values. COP-37 has lower adsorption capacity at lower pressure and lower temperature, which is contrary to all other materials. Nevertheless, the trend of isotherms in COP-37 returns back to the established conditions (i.e., higher adsorption at lower temperatures) only at high pressure. This unusual behavior of COP-37 for $\mathrm{CO}_{2}$ adsorption at the lower pressure range may be associated with the difference in the surface of this material, since COP-37 has different surface texture than all other COPs materials as can be noticed in the SEM images. Figure 6 further reveals that among the amide base materials, COP-34 has the lowest $\mathrm{CO}_{2}$ capacity whereas COP-32 and COP-33 has almost similar performance with a small increase of capacity in case of COP-33. On the other hand among the ester based materials, COP-36 has the lowest $\mathrm{CO}_{2}$ capturing capacity, while COP-35 has the largest adsorption capability, which is opposite to the performance of these materials at 1 bar and room temperature.

$\mathrm{CO}_{2}$ up take of all materials at $308 \mathrm{~K}$ and 200 bar has been compared in Figure 7, which reveals that adsorption capacity varies as COP-35 > COP-33 > COP-32 > COP-37 > COP-36 > COP-34. It must be noted COP-32 and COP-33 has almost similar performance at $308 \mathrm{~K}$ followed by COP-37, however, COP-36 and COP-34 fall in the same category with lowest adsorption under similar condition. Upon matching the physical properties of these compounds with adsorption capacity at $308 \mathrm{~K}$ and high pressure of $200 \mathrm{bar}$, it can be deduce that surface areas and pore volumes are not the driving 

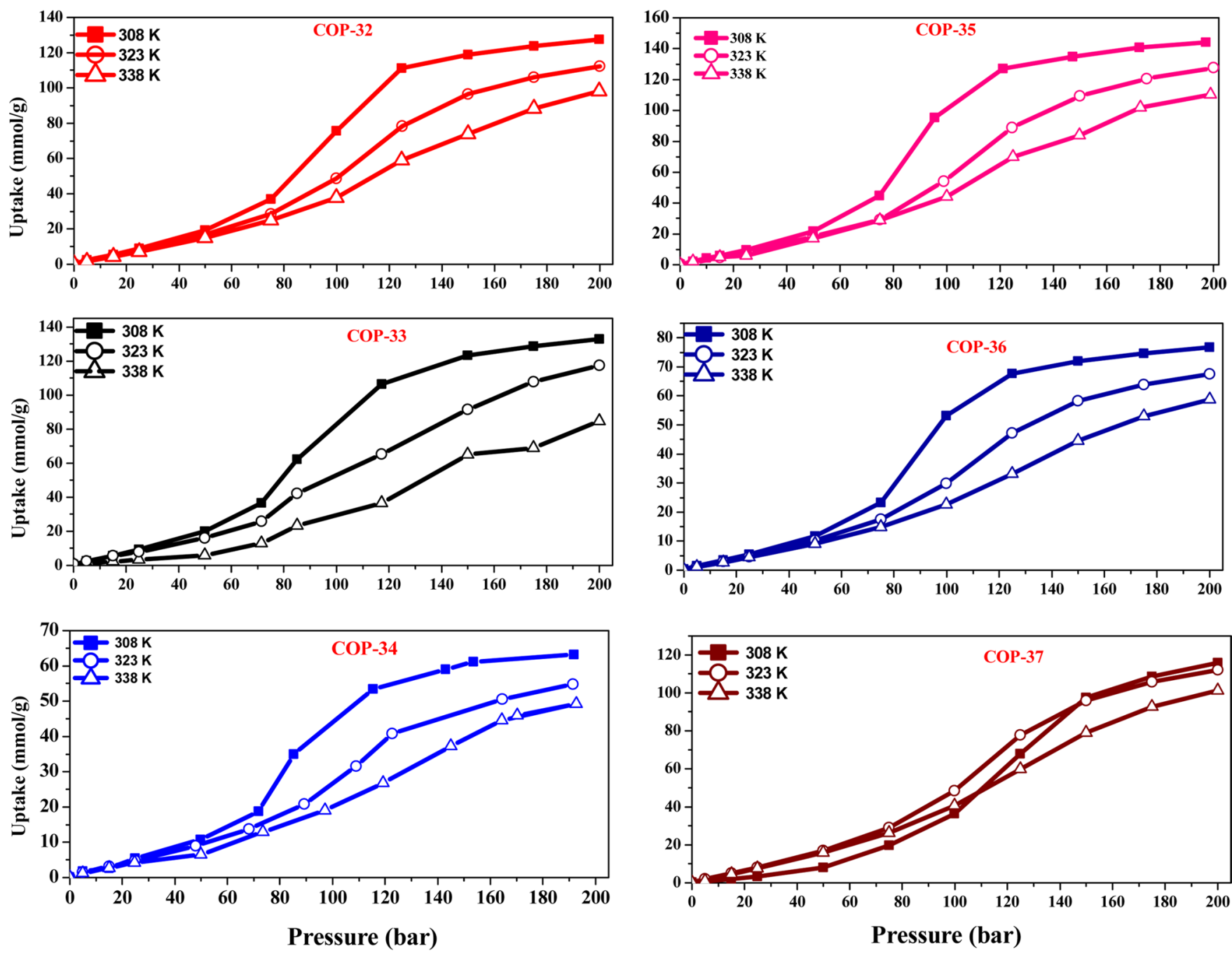

Figure 6. $\mathrm{CO}_{2}$ uptake by all COPs $(32-37)$ at 200 bar and 308, 323, and $338 \mathrm{~K}$.

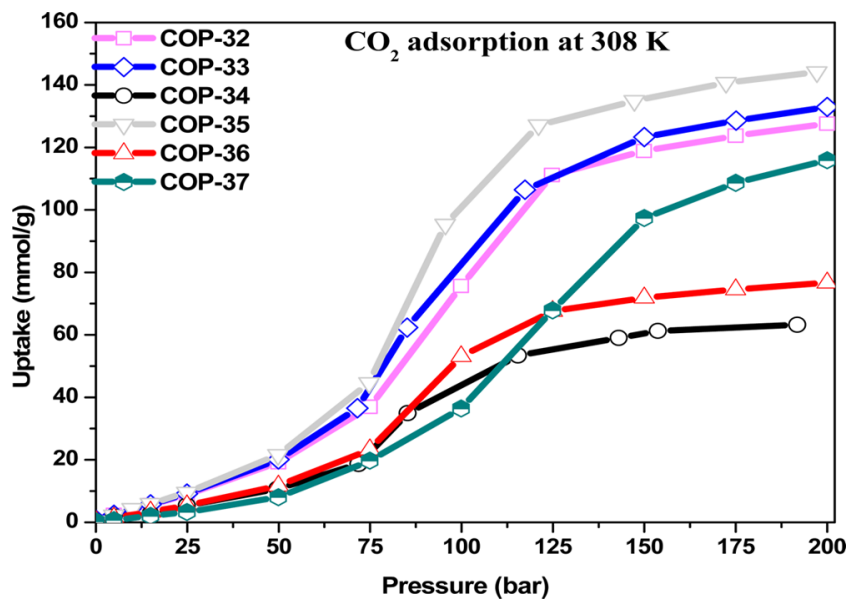

Figure 7. $\mathrm{CO}_{2}$ uptake by all COPs materials at $308 \mathrm{~K}$ and 200 bar.

forces for the maximum adsorption of COPs materials, since COP-35 has the lowest surface area of $5.4 \mathrm{~cm}^{3} / \mathrm{g}$ but has the largest capacity among all other materials. Similarly, Montagnaro et al. ${ }^{46}$ has recently compared the $\mathrm{CO}_{2}$ adsorption of two different activated carbon samples and showed that compound with lower pore volume has larger $\mathrm{CO}_{2}$ adsorption capacity than that which has almost double pore volume. As stated earlier, at lower pressure and lower temperature, physical properties of the materials may have influence on the adsorption capacities of these covalent organic polymers, however, at high pressure and high temperatures, $\mathrm{CO}_{2}$ affinity, active sites electrostatic interaction with adsorbate molecule and effect of pressure and temperature on the polarity of adsorbate and adsorbent, and on the physical properties (surface and pore volume) of materials may contribute to the enhanced $\mathrm{CO}_{2}$ adsorption. ${ }^{47}$

Similarly, nature and texture properties variations of COPs materials may also play important role in the adsorption capacity, since the surface functionality of ester-based materials (COP-35-37) are different than the amide based materials and will behave differently to the environmental condition of pressure and temperature which lead to the largest adsorption in case of COP-35 as compared to other counterparts. ${ }^{46}$ Main reason for the $\mathrm{CO}_{2}$ adsorption on the solid sorbent is the active sites such as as $-\mathrm{NH}_{2},-\mathrm{OH},-\mathrm{N}$, defect sites and electrostatic environment that surround these sites which leads to stronger interactions with surrounding $\mathrm{CO}_{2}$ environment around the specimen that is being tested. Additionally, variation in the adsorption mode and interaction of $\mathrm{CO}_{2}$ with different sites are different in case of amide and ester based materials and will definitely impact the adsorption capacity of these compounds at high pressure and high temperature. ${ }^{48}$ In case of amide-based 

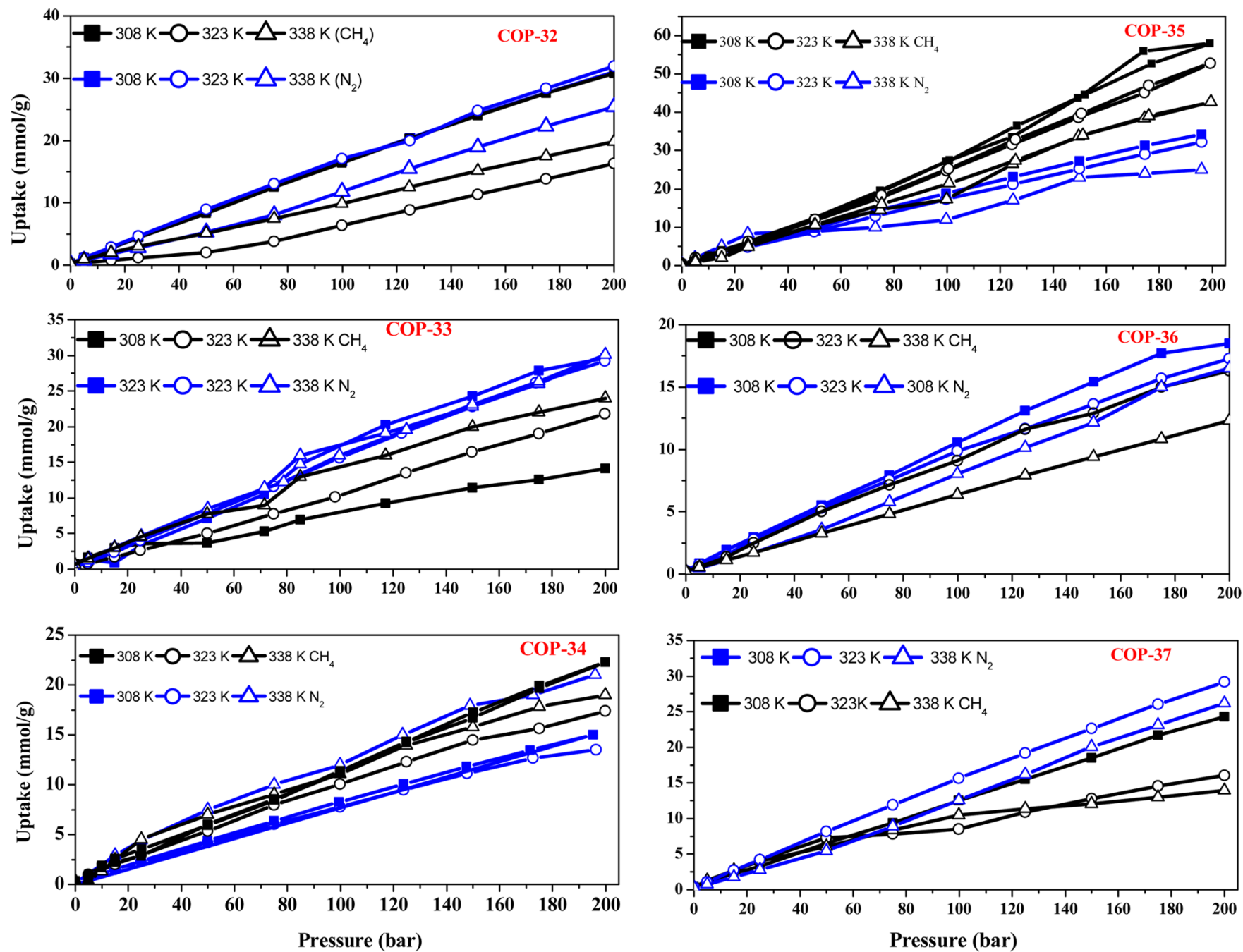

Figure 8. $\mathrm{CH}_{4}$ and $\mathrm{N}_{2}$ uptake by all COPs (32-37) at 200 bar and 308,323 , and $338 \mathrm{~K}$.

material (COP-32-34), nitrogen functionality is mainly responsible for $\mathrm{CO}_{2}$ adsorption which plays important role at lower pressure and temperature; however, in case of ester-based materials (COP-35-37) hydroxyl ion is the main function group on the surface of materials which can coordinate with $\mathrm{CO}_{2}$ molecule more effectively as compared to the $\mathrm{N}$ functionality at high pressure. ${ }^{48}$ Here in we assume that, at high pressure the defects sites on COP-35 surface become more favorable for $\mathrm{CO}_{2}$ molecules due to the enhancement in the strength of coulomb forces and Van der Waal forces resulting in increased adsorption capacity. ${ }^{49}$ Additionally, although COP-35 has the lowest surface area and less pore volume than other materials, however, it may have more defect sites containing $\mathrm{OH}$ ion on these sites which effectively capture $\mathrm{CO}_{2}$ with the support of mainly hydrogen bonding as evident in the literature. ${ }^{48}$ Liu et al. ${ }^{50}$ have predicted that oxygen containing functional group associated with the defect sites on the surface of solid adsorbents enhances adsorption of $\mathrm{CO}_{2}$ leading to the increased adsorption capacity. We therefore believe that COP-35 has more defect sites with associated oxygen function group as discussed in the literature ${ }^{51}$ which interact with the available adsorbate $\left(\mathrm{CO}_{2}\right)$ molecules more effectively at high pressure, thus leading to increased $\mathrm{CO}_{2}$ adsorption capacity.
All the materials were also tested for other gases, that is, $\mathrm{CH}_{4}$ and $\mathrm{N}_{2}$ at high pressure of 200 bar and three different temperatures to get the complete scenario of the materials behavior for adsorption of $\mathrm{CO}_{2}$ as well as other gases. Figure 8 compares the isotherms of $\mathrm{CH}_{4}$ and $\mathrm{N}_{2}$ of each material at three different temperatures and pressure of 200 bar, which reveal that COP-32 and COP-34 almost adsorb similar quantities of $\mathrm{CH}_{4}$ and $\mathrm{N}_{2}$, while COP-33 uptake more $\mathrm{N}_{2}$ than $\mathrm{CH}_{4}$ under similar condition of pressure and temperature. Additionally, ester based materials (COP-36 and COP-37) adsorb $\mathrm{N}_{2}$ more effectively than $\mathrm{CH}_{4}$, whereas COP-35 up take larger quantity of $\mathrm{CH}_{4}$ than $\mathrm{N}_{2}$ under similar pressure and temperature conditions. Detail discussion on the $\mathrm{CH}_{4}$ and $\mathrm{N}_{2}$ adsorption mechanism and behavior of COPs materials is out of the scope of the present study, however, the adsorption data was obtained in order to check the material interaction with gases other than $\mathrm{CO}_{2}$.

$\mathrm{H}_{2}$ adsorption capacities were measured in order to examine the expected application of these materials in precombustion capture and separation systems. All materials were subjected to same pressure of $200 \mathrm{bar}$ at sing temperature of $308 \mathrm{~K}$ to compare their $\mathrm{H}_{2}$ uptake capacity with $\mathrm{CO}_{2}$ adsorption capacity at similar conditions. Adsorption isotherms given in Figure 9 shows that COP-35 which has the largest $\mathrm{CO}_{2}$ capacity (144 $\mathrm{mmol} / \mathrm{g}$ ) can captures only $13 \mathrm{mmol} / \mathrm{g}$ of $\mathrm{H}_{2}$ at high pressure 


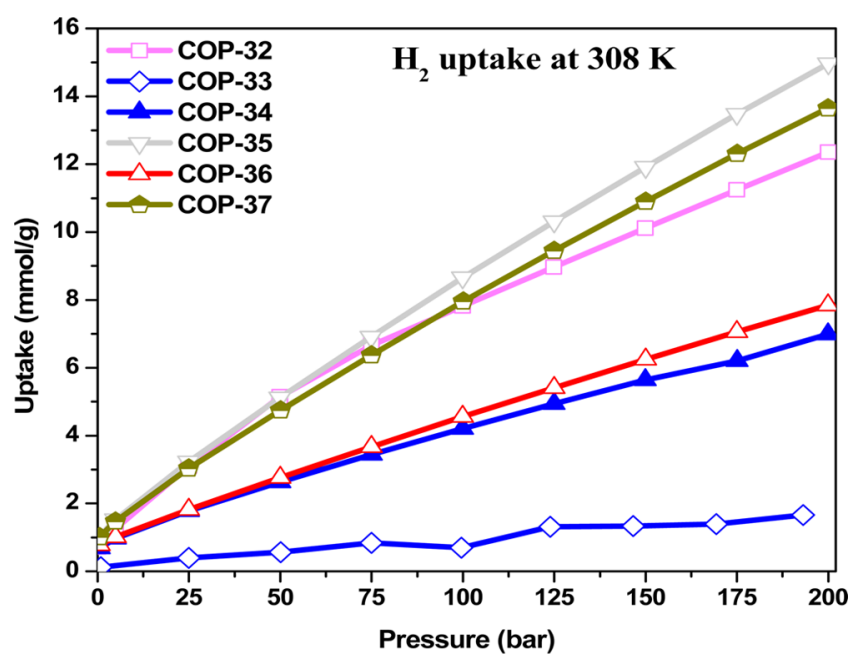

Figure 9. $\mathrm{H}_{2}$ adsorption data for all COPs materials at 200 bar and 308 K.

of 200 bar and $308 \mathrm{~K}$. On the other hand COP-33 adsorbed significantly less quantity of $\mathrm{H}_{2}(1.7 \mathrm{mmol} / \mathrm{g})$ as compared to other counterparts and hence the selectivity of this material is 78 for $\mathrm{CO}_{2} / \mathrm{H}_{2}$, which is the highest among all COPs materials.

Figure 10 and Table 5 show the data and overall performance of all COPs materials at three different temperatures $(308,323$,

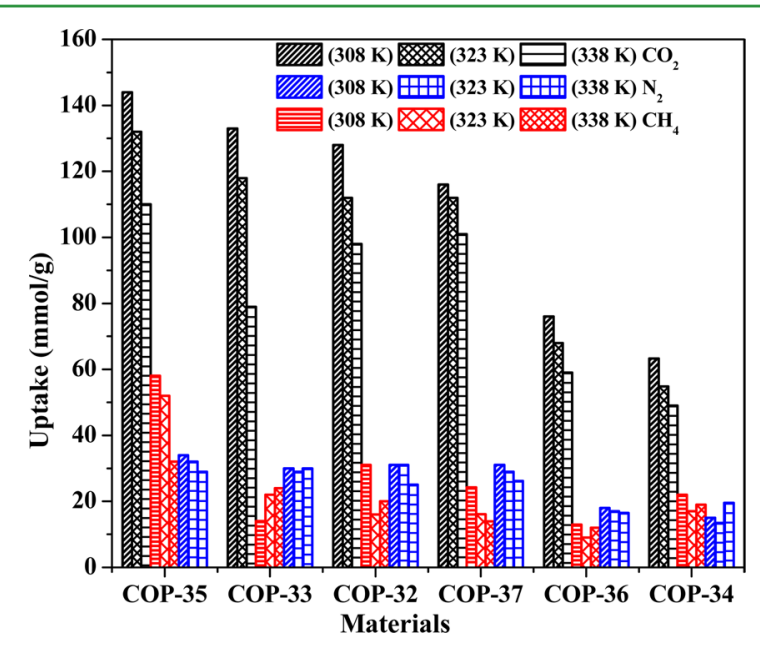

Figure 10. Overall performance of all materials for $\mathrm{CO}_{2}, \mathrm{CH}_{4}$, and $\mathrm{N}_{2}$ adsorption at $200 \mathrm{bar}$ and three different temperatures.

Table 5. Maximum Adsorption of $\mathrm{N}_{2}, \mathrm{CO}_{2}$, and $\mathrm{CH}_{4}$ by $\mathrm{COP}$ Materials at 200 bar

\begin{tabular}{|c|c|c|c|c|c|c|c|c|c|}
\hline \multirow[b]{3}{*}{ material } & \multicolumn{3}{|c|}{$\mathrm{CO}_{2}(\mathrm{mmol} / \mathrm{g})$} & \multirow{2}{*}{\multicolumn{3}{|c|}{$\frac{\mathrm{CH}_{4}(\mathrm{mmol} / \mathrm{g})}{\text { temperature }(\mathrm{K})}$}} & \multicolumn{3}{|c|}{$\mathrm{N}_{2}(\mathrm{mmol} / \mathrm{g})$} \\
\hline & & & & & & & & & \\
\hline & 308 & 323 & 338 & 308 & 323 & 338 & 308 & 323 & 338 \\
\hline COP-32 & 128 & 112 & 98 & 31 & 16 & 20 & 31 & 31 & 25 \\
\hline COP-33 & 133 & 118 & 79 & 14 & 22 & 24 & 30 & 29 & 30 \\
\hline COP-34 & 63 & 55 & 49 & 22 & 17 & 19 & 15 & 14 & 20 \\
\hline COP-35 & 144 & 128 & 110 & 58 & 52 & 42 & 34 & 32 & 29 \\
\hline COP-36 & 76 & 68 & 59 & 18 & 16 & 12 & 18 & 17 & 16.5 \\
\hline COP-37 & 116 & 112 & 101 & 24 & 16 & 14 & 31 & 29 & 26 \\
\hline
\end{tabular}

and $338 \mathrm{~K}$ ) for the maximum adsorption of $\mathrm{CO}_{2}, \mathrm{CH}_{4}$, and $\mathrm{N}_{2}$ at 200 bar. It is evident from Figure 10 and Table 5 that COP35 uptakes the maximum $\mathrm{CO}_{2}$ quantity of about $144 \mathrm{mmol} / \mathrm{g}$ at
$308 \mathrm{~K}$ which is known to be the largest capturing capacity of solid sorbent, recorded for the first time in the literature under similar condition. However, owing to the exothermic effect of the adsorption process $\mathrm{CO}_{2}$ up take was reduced to 128 and $110 \mathrm{mmol} / \mathrm{g}$ at higher temperature of 323 and $33 \mathrm{~K}$. Upon comparing the capturing capacity of materials at $308 \mathrm{~K}$ and 200 bar, it can be seen that maximum adsorption capacity for $\mathrm{CO}_{2}$ varies as $\mathrm{COP}-35>\mathrm{COP}-33>\mathrm{COP}-32>\mathrm{COP}-37>\mathrm{COP}-36>$ COP-34, which is irrelative to the physical properties such as pore volume and surface areas of materials. Figure 10 and Table 5 also represent the adsorption capacities of these materials under similar condition for $\mathrm{CH}_{4}$ and $\mathrm{N}_{2}$, it can be seen that with a minute difference all the materials almost behave similarly for gases other than $\mathrm{CO}_{2}$. However, at low pressure this trend of $\mathrm{CH}_{4}$ and $\mathrm{N}_{2}$ adsorption was different than that at high pressure, since at low pressure of $10 \mathrm{bar}$, COP-36 and COP-37 even could not up take any $\mathrm{N}_{2}$ giving rise very high selectivity for $\mathrm{CO}_{2} / \mathrm{N}_{2}$.

Selectivity of COPs materials at high pressure of 200 bar and three different temperatures given in Table 6 indicates that

Table 6. Selectivity of COP Materials at 200 bar

\begin{tabular}{|c|c|c|c|}
\hline \multirow[b]{3}{*}{ material } & \multicolumn{3}{|c|}{ temperature $(\mathrm{K})$} \\
\hline & 308 & 323 & 338 \\
\hline & $\mathrm{CO}_{2}: \mathrm{CH}_{4}: \mathrm{N}$ & $\mathrm{CO}_{2}: \mathrm{CH}_{4}: \mathrm{N}$ & $\mathrm{CO}_{2}: \mathrm{CH}_{4}: \mathrm{N}_{2}$ \\
\hline COP-32 & $4: 1: 1$ & $7: 1: 2$ & $5: 1: 1$ \\
\hline COP-33 & $10: 1: 2$ & $5: 1: 1$ & $4: 1: 2$ \\
\hline COP-34 & $4: 1: 1$ & $4: 1: 1$ & $3: 1: 1$ \\
\hline COP-35 & $4: 2: 1$ & $4: 2: 1$ & $4: 2: 1$ \\
\hline COP-36 & $6: 1: 1$ & $7: 1: 2$ & $5: 1: 1$ \\
\hline COP-37 & $5: 1: 1$ & $7: 1: 2$ & $7: 1: 2$ \\
\hline
\end{tabular}

along with the highest adsorption capacity COP-35 also have best selectivity among all other materials. Selectivity was calculated based on single gas sorption data collection at a time getting the normalized sorption data among the gas sorption values. As shown in Table 6 selectivity of COP-33 for $\mathrm{CO}_{2}: \mathrm{CH}_{4}: \mathrm{N}_{2}$ is $10: 1: 2$ at $308 \mathrm{~K}$ which is highest among all other followed by COP-36 with the selectivity of $6: 1: 1$ at 308 . It must also be noted that selectivity of COP-35 is almost comparable to COP-34 where both are about stable at all other temperatures of 323 and $338 \mathrm{~K}$ whereas selectivity of COP-33 reduced to 5:1:1 and 4:1:2 under similar conditions. It is important to note that although, COP-35 has comparatively similar selectivity to COP-34 however, the former has the highest adsorption capacity whereas the later has the lowest adsorption capacity.

Since adsorption is exothermic process and lot of heat is liberated when adsorption take place on the adsorbent surface, $^{52}$ we therefore calculate the heat of adsorption (shown in Figure 11) for each material at $308 \mathrm{~K}$ using Clapeyron equation at particular number moles of $\mathrm{CO}_{2}$ captured by the adsorbents. ${ }^{53}$ As shown in Figure 11, the material with largest adsorption quantity has highest heat of adsorption, which is decreasing rapidly with increasing the number of adsorbed mole on the materials surfaces. COP-35 has the highest heat of adsorption followed by COP-33, COP32 and COP-37, which is similar to the adsorption trend of $\mathrm{CO}_{2}$ (Figure 7). Additionally, COP-34 and COP-36 have the lowest adsorption as well as lowest heat of adsorption, which 


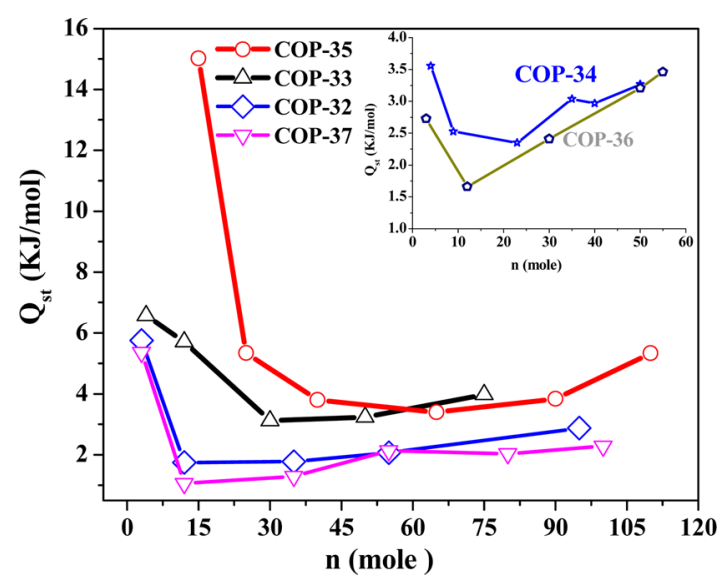

Figure 11. Heat of adsorption associated with $\mathrm{CO}_{2}$ adsorption at 308 K.

represent the lower performance of these two materials for $\mathrm{CO}_{2}$ up take.

A detailed investigation of Figure 11 indicates that for all materials isosteric heat of adsorption initially decreasing immediately form the largest value, become flatten and then increases a little bit as the adsorbed number of moles increases. Krungleviciute et al. ${ }^{54}$ also observed almost similar trend in the isosteric heat of adsorption for the carbon nanotube, where increase in the heat of adsorption at high surface coverage was attributed to the intrainteraction of adsorbate molecules on the surface.

Although, COP-35 has $15.01 \mathrm{~kJ} / \mathrm{mol}$ heat of adsorption which is the largest among all other COPs materials, however, this is much lower than that of other physical adsorbents such as polymers $(20.3 \mathrm{~kJ} / \mathrm{mol}),{ }^{55}$ metal organic frame-works $(90$ $\mathrm{kJ} / \mathrm{mol}),{ }^{56}$ zeolites $(50 \mathrm{~kJ} / \mathrm{mol}),{ }^{57}$ and functionalized silica $(100 \mathrm{~kJ} / \mathrm{mol})$. Riech et al. ${ }^{58}$ found that a nanoporous borazinelinked polymer (BLP-1) has $22.2 \mathrm{~kJ} / \mathrm{mol}$ heat of adsorption which is least among all other materials for $\mathrm{CO}_{2}$ however, this material has very low selectivity for $\mathrm{CO}_{2}$ over methane. It is evident that, COPs material possesses very low heat of adsorption, which makes these compounds more favorable as long as regeneration and repeated use of the adsorbents are concern.

As an essential property of adsorption-desorption process, rate of adsorption was calculated via mathematical expression mentioned in literature ${ }^{59}$ in the term of mass transfer coefficient $\mathrm{k}(1 / \mathrm{sec})$ (shown in Figure 12) at two different temperatures and pressure of 10 bar from the adsorbed quantity of $\mathrm{CO}_{2}$ at particular pressure values. It is important to note that although COP-33 comparatively adsorbed more $\mathrm{CO}_{2}$ at 10 bar, however, its rate of adsorption is significantly slower than all other materials. Additionally, Figure 12 further reveals that at $298 \mathrm{~K} \mathrm{COP}-37$ up take $\mathrm{CO}_{2}$ with the fastest rate of about 0.94/ sec followed by COP-33 and COP-34, whereas COP-35 and COP-36 have almost similar adsorption rate starting at around $0.5 / \mathrm{sec}$. Figure 12 further indicates that in general rate of adsorption reduces for all the materials with the increase of temperature, however, in case of COP-32 temperature has negligible effect on mass transfer co efficient. Unlike to Brownian motion of gases, reduction in the rate of adsorption on the adsorbent surfaces and within the pore at high temperature is obviously due the exothermic effect of adsorption, which hinders both the adsorption capacity and moment of adsorbate on the surfaces. Since, mass transfer coefficient of $\mathrm{CO}_{2}$ in ammonia absorption is restricted by the gas-liquid interface and the different environmental condition surrounding the gas molecules in aqueous ammonia, ${ }^{60}$ similarly, the moment of $\mathrm{CO}_{2}$ on solid surfaces and inside the pore is also restricted by hydrogen bonding and Van der Waal forces between adsorbate and adsorbent. Additionally, surface heterogeneity also plays important role in the adsorption process which may subsequently leads to the enhancement in heat of adsorption, as well as to the reduction in the rate of adsorption. Boa et al. noted that all gases including $\mathrm{CO}_{2}$ and methane adsorbed quickly and the equilibrium achieves rapidly with increase in temperature using metal organic frameworks as sorbent, however, in our case as shown in Figure 12, $\mathrm{CO}_{2}$ adsorption becomes slower with increase in temperature. ${ }^{61}$

In situ FTIR analysis was conducted using COP-35 as solid sorbent to ensure the interaction of $\mathrm{CO}_{2}$ molecules with attractive sites. In a typical procedure $\mathrm{KBr}$ powder and $\mathrm{COP}-35$ were mixed with proper ratio and then dehydrated for at least $12 \mathrm{~h}$ to completely remove water content form the mixture. Initially, background spectrum of only $\mathrm{KBr}$ pellet under vacuum was collected in order to obtain pure spectrum of only $\mathrm{CO}_{2}$ and COP-35. It is important to note that only single peak at 2337.5 $\mathrm{cm}^{-1}$ is observed upon injecting $\mathrm{CO}_{2}$ at room temperature as shown in Figure 13, which is assigned to the residual gaseous $\mathrm{CO}_{2}$ in the atmosphere of the sample and detector compartments which could not be resolved by purging. The peak at $2337.5 \mathrm{~cm}^{-1}$ grows as $\mathrm{CO}_{2}$ pressure increases, overriding the infrared absorbance of gaseous $\mathrm{CO}_{2}$ peak at $2349 \mathrm{~cm}^{-1}$ until

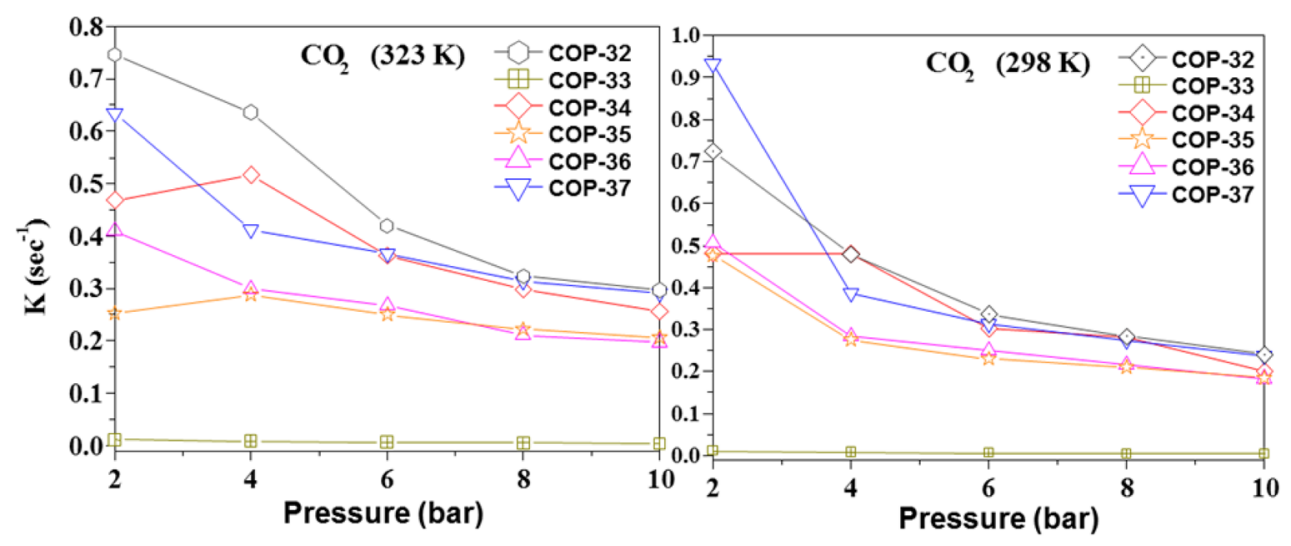

Figure 12. Rate of adsorption calculated from data of $\mathrm{CO}_{2}$ adsorption at $298 \mathrm{~K}, 323 \mathrm{~K}$, and 10 bar. 

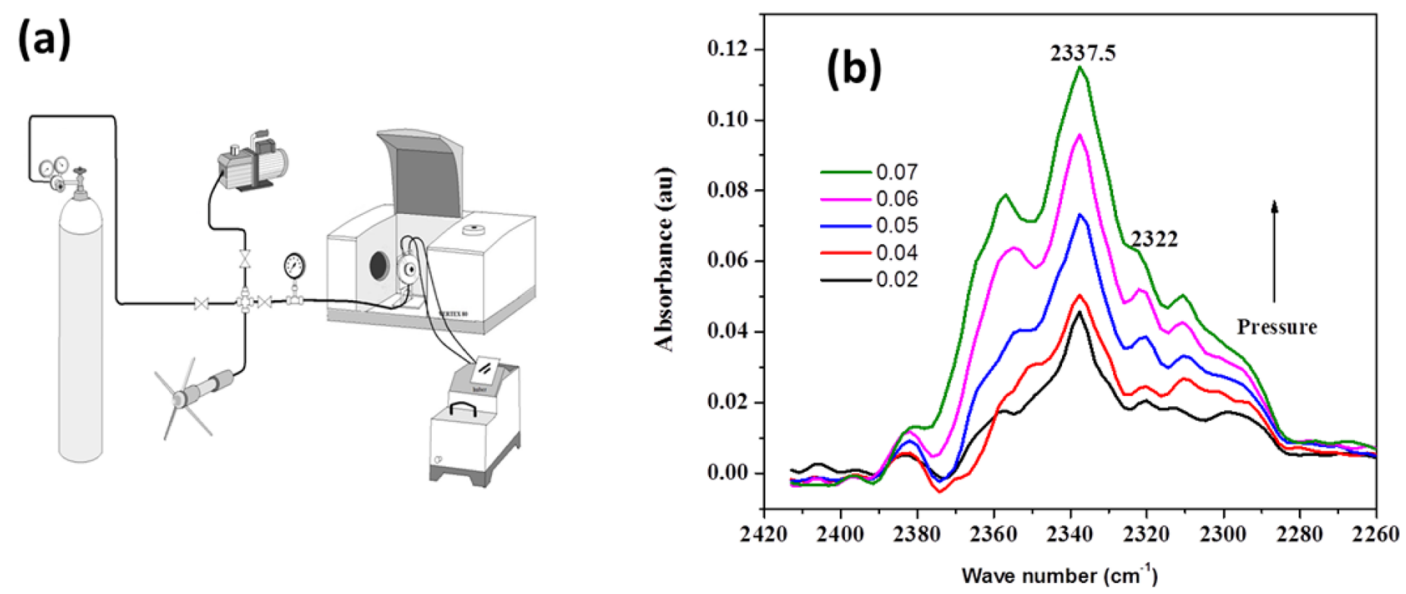

Figure 13. In situ FTIR (a) set up and (b) analysis of $\mathrm{CO}_{2}$ adsorption by COP-35 at various pressure ranges.

the former prevails at 0.07 bar. This heterogeneous interaction is allowed for six to $8 \mathrm{~min}$ to ensure saturation at each pressure. The peak at $2337.5 \mathrm{~cm}^{-1}$ is assigned to $\mathrm{CO}_{2}$ asymmetric stretch mode that is red-shifted with respect to the peak of gaseous $\mathrm{CO}_{2}$, providing an evidence for the presence of at least one type of sorption sites which is responsible for $\mathrm{CO}_{2}$ uptake by COP35. As the pressure increases, the absorbance of infrared photons increases which indicates that $\mathrm{CO}_{2}$ adsorbed quantity increases along with pressure. It is important to note that vibrational frequency of asymmetric stretching mode of adsorbed $\mathrm{CO}_{2}$ on graphene surface ${ }^{62}$ was observed at 2393 $\mathrm{cm}^{-1}$, while it was detected at $2319 \mathrm{~cm}^{-1}$ on graphite nanoparticles. ${ }^{63}$ Contrary, in situ FTIR analysis of yttriastabilized $\mathrm{ZrO}_{2}, \mathrm{Y}_{2} \mathrm{O}_{3}$, and pristine $\mathrm{ZrO}_{2}$ showed that most of the adsorbed $\mathrm{CO}_{2}$ has been chemically bonded to form various carbonate species via chemisorption process due the presence of hydroxyl group on the surfaces. ${ }^{64}$ In our case no evidence of chemisorption was detected which indicates that COP-35 uptake $\mathrm{CO}_{2}$ only through physical adsorption, that is, via Vander Waal interaction and columbic interaction and could be a suitable material for further investigation.

\section{CONCLUSION}

Six different types of covalent organic polymers (COPs) with two different functionalities, that is, $\mathrm{OH}$ group and $\mathrm{N}_{2}$ based on different linkers and single building block monomers have been successfully prepared and were tested for adsorption of $\mathrm{CO}_{2}$, $\mathrm{CH}_{4}$, and $\mathrm{N}_{2}$ at various temperatures and pressures. Results showed that at atmospheric condition ( 1 bar and $298 \mathrm{~K}$ ) $\mathrm{CO}_{2}$ adsorption capacities of materials were mostly dependent on the physical parameters i.e. surface areas and pores volume of these materials, therefore, COP-33 uptakes more $\mathrm{CO}_{2}$ than other COPs materials. On the other hand COP-35 has the smallest surface area among all materials, which makes this material less capable to adsorb $\mathrm{CO}_{2}$ at these pressure and temperature conditions. Results further revealed that at pressure of $10 \mathrm{bar}, \mathrm{CO}_{2}$ adsorption capacities of amides (COP-32, COP-33, and COP-34) are strongly related to their pores volume and surface areas, since, $\mathrm{CO}_{2}$ adsorption capacities of amides have similar trend to that of the pore volume $\left(0.2>0.139>0.095 \mathrm{~cm}^{3} / \mathrm{g}\right)$ and surface areas. It was also noticed that amides also adsorb certain quantity of $\mathrm{N}_{2}$ and $\mathrm{CH}_{4}$ in addition to $\mathrm{CO}_{2}$, however, ester based materials are totally inactive for $\mathrm{N}_{2}$ and $\mathrm{CH}_{4}$ at 10 bar and temperatures of 298 and $323 \mathrm{~K}$. Unlike to lower pressure, performances of ester materials (COP-35, COP-36, and COP-37) were different than amide type materials at high pressure of 200 bar. Interestingly, although COP-35 has the lowest surface area among all materials, however, it up take $144 \mathrm{mmol} / \mathrm{g} \mathrm{CO}_{2}$ at $308 \mathrm{~K}$ and 200 bar, which is the largest quantity adsorbed by any solid sorbent so far in the literature. The largest adsorption capacity of COP-35 than any other materials can be attributed to the presence of defects sites on the surface, making this material more favorable for $\mathrm{CO}_{2}$ molecules adsorption because of the enhancement in the strength of coulomb and van der Waals forces at high-pressure valves. Since, COP-35 adsorb largest quantity of $\mathrm{CO}_{2}$, therefore, it has the largest heat of adsorption $(15 \mathrm{~kJ} / \mathrm{mol})$ among all COPs materials, but less than any other solid sorbent reported in the literature. In addition to the quantitative investigations, kinetics measurement of $\mathrm{CO}_{2}$ adsorption conducted at $10 \mathrm{bar}$ and two different temperatures revealed that COP-37 has the best while COP-33 has the lowest rate of adsorption than all other materials. COPs materials were also. On the other hand COP-33 has the best selectivity for $\mathrm{CO}_{2}: \mathrm{CH}_{4}: \mathrm{N}_{2}$, which is $10: 1: 2$ at $308 \mathrm{~K}$ and 200 bar, however, at atmospheric condition this material has much higher selectivity of $32: 1$ for $\mathrm{CO}_{2}: \mathrm{N}_{2}$. It can be deduced from the presented findings that, COP-33 has the best performance at atmospheric condition and lower pressure; however, COP-35 has shown very interesting results at high pressure of 200 bar by adsorbing the largest quantity of $\mathrm{CO}_{2}$ so far. On the basis of these findings, it can be suggested that COP-35 needs to be further investigated at various pressure and temperature conditions including pressure swing adsorption and humidity effect on the adsorption capacity.

\section{ASSOCIATED CONTENT}

\section{S Supporting Information}

The Supporting Information is available free of charge on the ACS Publications website at DOI: 10.1021/acsami.6b05927.

Detailed synthesis of the presented COP materials, characterization data for FTIR and BET measurements, and selectivity data based on single gas adsorption (PDF)

\section{AUTHOR INFORMATION}

\section{Corresponding Authors}

*E-mail: mert.atilhan@qu.edu.qa.

*E-mail: yavuz@kaist.ac.kr. 


\section{Author Contributions}

${ }^{\#}$ Equal contribution.

\section{Notes}

The authors declare no competing financial interest.

\section{ACKNOWLEDGMENTS}

This paper was made possible by the support of Qatar National Research Fund, National Priorities Research Program grant (NPRP 5-499-1-088). The statements made herein are solely the responsibility of the authors.

\section{REFERENCES}

(1) Barandica, J. M.; Delgado, J. A.; Berzosa, Á.; Fernández-Sánchez, G.; Serrano, J. M.; Zorrilla, J. M. Estimation of $\mathrm{CO} 2$ emissions in the life cycle of roads through the disruption and restoration of environmental systems. Ecological Engineering 2014, 71, 154-164.

(2) Berger, A. H.; Bhown, A. S. Selection of Optimal Solid Sorbents for $\mathrm{CO} 2$ Capture Based on Gas Phase $\mathrm{CO} 2$ composition. Energy Procedia 2014, 63 (0), 2092-2099.

(3) Liu, X.; Zhang, Y.; Li, H.; A, S.; Xia, H.; Mu, Y. Triarylboronbased fluorescent conjugated microporous polymers. RSC Adv. 2013, 3 (44), 21267-21270.

(4) Ullah, R.; Atilhan, M.; Diab, A.; Deniz, E.; Aparicio, S.; Yavuz, C. T. Synthesis, characterization and evaluation of porous polybenzimidazole materials for $\mathrm{CO} 2$ adsorption at high pressures. Adsorption 2016, 22, 247-260.

(5) Belmabkhout, Y.; Guillerm, V.; Eddaoudi, M. Low concentration $\mathrm{CO} 2$ capture using physical adsorbents: Are metal-organic frameworks becoming the new benchmark materials? Chem. Eng. J. 2016, 296, 386-397.

(6) Prudencio, A.; Schmeltzer, R. C.; Uhrich, K. E. Effect of Linker Structure on Salicylic Acid-Derived Poly(anhydride-esters). Macromolecules 2005, 38 (16), 6895-6901.

(7) Liu, G.; Wang, Y.; Shen, C.; Ju, Z.; Yuan, D. A facile synthesis of microporous organic polymers for efficient gas storage and separation. J. Mater. Chem. A 2015, 3, 3051-3058.

(8) Patel, H. A.; Ko, D.; Yavuz, C. T. Nanoporous Benzoxazole Networks by Silylated Monomers, Their Exceptional Thermal Stability, and Carbon Dioxide Capture Capacity. Chem. Mater. 2014, 26, 6729-6733.

(9) Patel, H. A.; Karadas, F.; Canlier, A.; Park, J.; Deniz, E.; Jung, Y.; Atilhan, M.; Yavuz, C. T. High capacity carbon dioxide adsorption by inexpensive covalent organic polymers. J. Mater. Chem. 2012, 22 (17), 8431-8437.

(10) Liebl, M. R.; Senker, J. Microporous Functionalized TriazineBased Polyimides with High CO2 Capture Capacity. Chem. Mater. 2013, 25 (6), 970-980.

(11) El-Kaderi, H. M.; Hunt, J. R.; Mendoza-Cortés, J. L.; Côté, A. P.; Taylor, R. E.; O'Keeffe, M.; Yaghi, O. M. Designed Synthesis of 3D Covalent Organic Frameworks. Science 2007, 316 (5822), 268-272.

(12) McKeown, N. B.; Budd, P. M. Polymers of intrinsic microporosity (PIMs): organic materials for membrane separations, heterogeneous catalysis and hydrogen storage. Chem. Soc. Rev. 2006, 35 (8), 675-683.

(13) Sekizkardes, A. K.; Islamoglu, T.; Kahveci, Z.; El-Kaderi, H. M. Application of pyrene-derived benzimidazole-linked polymers to $\mathrm{CO} 2$ separation under pressure and vacuum swing adsorption settings. J. Mater. Chem. A 2014, 2 (31), 12492-12500.

(14) Xiao, Q.; Liu, Y.; Zhong, Y.; Zhu, W. A citrate sol-gel method to synthesize $\mathrm{Li} 2 \mathrm{ZrO} 3$ nanocrystals with improved $\mathrm{CO} 2$ capture properties. J. Mater. Chem. 2011, 21 (11), 3838-3842.

(15) Kato, M.; Nakagawa, K.; Essaki, K.; Maezawa, Y.; Takeda, S.; Kogo, R.; Hagiwara, Y. Novel CO2 Absorbents Using LithiumContaining Oxide. Int. J. Appl. Ceram. Technol. 2005, 2 (6), 467-475.

(16) Zhang, X.; Long, E.; Li, Y.; Guo, J.; Zhang, L.; Gong, M.; Wang, M.; Chen, Y. CeO2-ZrO2-La2O3-Al2O3 composite oxide and its supported palladium catalyst for the treatment of exhaust of natural gas engined vehicles. J. Nat. Gas Chem. 2009, 18 (2), 139-144.

(17) Bai, R.; Yang, M.; Hu, G.; Xu, L.; Hu, X.; Li, Z.; Wang, S.; Dai, W.; Fan, M. A new nanoporous nitrogen-doped highly-efficient carbonaceous $\mathrm{CO} 2$ sorbent synthesized with inexpensive urea and petroleum coke. Carbon 2015, 81 (0), 465-473.

(18) Wu, Z.; Webley, P. A.; Zhao, D. Post-enrichment of nitrogen in soft-templated ordered mesoporous carbon materials for highly efficient phenol removal and CO2 capture. J. Mater. Chem. 2012, 22 (22), 11379-11389.

(19) Xing, W.; Liu, C.; Zhou, Z.; Zhou, J.; Wang, G.; Zhuo, S.; Xue, Q.; Song, L.; Yan, Z. Oxygen-containing functional group-facilitated $\mathrm{CO}(2)$ capture by carbide-derived carbons. Nanoscale Res. Lett. 2014, 9 (1), 189-189.

(20) Sánchez-Sánchez, Á.; Suárez-García, F.; Martínez-Alonso, A.; Tascón, J. M. D. Influence of Porous Texture and Surface Chemistry on the CO2 Adsorption Capacity of Porous Carbons: Acidic and Basic Site Interactions. ACS Appl. Mater. Interfaces 2014, 6 (23), 2123721247.

(21) Zulfiqar, S.; Sarwar, M. I. Probing the potential of polyester for CO2 capture. J. Environ. Sci. 2014, 26 (7), 1423-1427.

(22) Karadas, F.; Yavuz, C. T.; Zulfiqar, S.; Aparicio, S.; Stucky, G. D.; Atilhan, M. CO2 Adsorption Studies on Hydroxy Metal Carbonates $\mathrm{M}(\mathrm{CO} 3) \mathrm{x}(\mathrm{OH})$ y $(\mathrm{M}=\mathrm{Zn}, \mathrm{Zn}-\mathrm{Mg}, \mathrm{Mg}, \mathrm{Mg}-\mathrm{Cu}, \mathrm{Cu}$, $\mathrm{Ni}$, and $\mathrm{Pb}$ ) at High Pressures up to 175 bar. Langmuir 2011, 27 (17), 10642-10647.

(23) Lemmon, E. W., Huber, M. L., McLinden, M. O. NIST Standard Reference Database 23: Reference Fluid Thermodynamic and Transport Properties-REFPROP, version 9.1; National Institute of Standards and Technology, Standard Reference Data Program: Gaithersburg, MD, 2013.

(24) Mantilla, I. D.; Cristancho, D. E.; Ejaz, S.; Hall, K. R.; Atilhan, M.; Iglesias-Silva, G. A. P- $\rho$-T data for carbon dioxide from (310 to 450) K up to $160 \mathrm{MPa}$. J. Chem. Eng. Data 2010, 55 (11), 4611-4613.

(25) Pattabiraman, V. R.; Bode, J. W. Rethinking amide bond synthesis. Nature 2011, 480 (7378), 471-479.

(26) Patel, H. A.; Yavuz, M. S.; Yavuz, C. T. Exceptional organic solvent uptake by disulfide-linked polymeric networks. RSC Adv. 2014, 4 (46), 24320-24323.

(27) Worzakowska, M. TG/FTIR/QMS studies of long chain esters of geraniol. J. Anal. Appl. Pyrolysis 2014, 110 (0), 181-193.

(28) Young, S. K.; Gemeinhardt, G. C.; Sherman, J. W.; Storey, R. F.; Mauritz, K. A.; Schiraldi, D. A.; Polyakova, A.; Hiltner, A.; Baer, E. Covalent and non-covalently coupled polyester-inorganic composite materials. Polymer 2002, 43 (23), 6101-6114.

(29) Patel, H. A.; Sang, H. J.; Park, J.; Chen, D. P.; Jung, Y.; Yavuz, C. T.; Coskun, A. Unprecedented high-temperature $\mathrm{CO} 2$ selectivity in N2-phobic nanoporous covalent organic polymers. Nat. Commun. 2013, 4, 1357.

(30) Mason, C. R.; Maynard-Atem, L.; Heard, K. W. J.; Satilmis, B.; Budd, P. M.; Friess, K.; Lanč, M.; Bernardo, P.; Clarizia, G.; Jansen, J. C. Enhancement of $\mathrm{CO} 2$ Affinity in a Polymer of Intrinsic Microporosity by Amine Modification. Macromolecules 2014, 47 (3), 1021-1029.

(31) Sun, Z.; Li, Y.; Guan, X.; Chen, L.; Jing, X.; Xie, Z. Rational design and synthesis of covalent organic polymers with hollow structure and excellent antibacterial efficacy. RSC Adv. 2014, 4 (76), 40269-40272.

(32) Chiou, K.; Hollanger, E.; Agag, T.; Ishida, H. Highly Improved Thermal Properties of Hydroxyl-Containing Polymers via Modification by Benzoxazine Groups. Macromol. Chem. Phys. 2013, 214, 16291635.

(33) Dawson, R.; Cooper, A. I.; Adams, D. J. Nanoporous organic polymer networks. Prog. Polym. Sci. 2012, 37 (4), 530-563.

(34) Thi, T. H.; Matsusaki, M.; Hirano, H.; Kawano, H.; Agari, Y.; Akashi, M. Mechanism of high thermal stability of commercial polyesters and polyethers conjugated with bio-based caffeic acid. $J$. Polym. Sci., Part A: Polym. Chem. 2011, 49 (14), 3152-3162. 
(35) Seredych, M.; Jagiello, J.; Bandosz, T. J. Complexity of CO2 adsorption on nanoporous sulfur-doped carbons - Is surface chemistry an important factor? Carbon 2014, 74 (0), 207-217.

(36) Kipling, J. J.; Sherwood, J. N.; Shooter, P. V.; Thompson, N. R. The pore structure and surface area of high-temperature polymer carbons. Carbon 1964, 1 (3), 321-328.

(37) Meng, L.-Y.; Park, S.-J. MgO-templated porous carbons-based $\mathrm{CO} 2$ adsorbents produced by $\mathrm{KOH}$ activation. Mater. Chem. Phys. 2012, 137 (1), 91-96.

(38) Rouquerol, F.; Rouquerol, J.; Sing, K. Interpretation of Physisorption Isotherms at the Gas-Solid Interface. In Adsorption by Powders and Porous Solids; Rouquerol, F., Rouquerol, J., Sing, K., Eds.; Academic Press: London, 1999; Chapter 4, pp 93-115.

(39) Xiang, Z.; Cao, D.; Wang, W.; Yang, W.; Han, B.; Lu, J. Postsynthetic Lithium Modification of Covalent-Organic Polymers for Enhancing Hydrogen and Carbon Dioxide Storage. J. Phys. Chem. C 2012, 116 (9), 5974-5980.

(40) Xiang, Z.; Cao, D. Synthesis of Luminescent Covalent-Organic Polymers for Detecting Nitroaromatic Explosives and Small Organic Molecules. Macromol. Rapid Commun. 2012, 33 (14), 1184-1190.

(41) Ben, T.; Ren, H.; Ma, S.; Cao, D.; Lan, J.; Jing, X.; Wang, W.; $\mathrm{Xu}$, J.; Deng, F.; Simmons, J. M.; Qiu, S.; Zhu, G. Targeted Synthesis of a Porous Aromatic Framework with High Stability and Exceptionally High Surface Area. Angew. Chem., Int. Ed. 2009, 48 (50), 94579460.

(42) Yuan, D.; Lu, W.; Zhao, D.; Zhou, H.-C. Highly Stable Porous Polymer Networks with Exceptionally High Gas-Uptake Capacities. Adv. Mater. 2011, 23 (32), 3723-3725.

(43) Boot-Handford, M. E.; Abanades, J. C.; Anthony, E. J.; Blunt, M. J.; Brandani, S.; Mac Dowell, N.; Fernandez, J. R.; Ferrari, M.-C.; Gross, R.; Hallett, J. P.; Haszeldine, R. S.; Heptonstall, P.; Lyngfelt, A.; Makuch, Z.; Mangano, E.; Porter, R. T. J.; Pourkashanian, M.; Rochelle, G. T.; Shah, N.; Yao, J. G.; Fennell, P. S. Carbon capture and storage update. Energy Environ. Sci. 2014, 7 (1), 130-189.

(44) Walton, K. S.; Millward, A. R.; Dubbeldam, D.; Frost, H.; Low, J. J.; Yaghi, O. M.; Snurr, R. Q. Understanding Inflections and Steps in Carbon Dioxide Adsorption Isotherms in Metal-Organic Frameworks. J. Am. Chem. Soc. 2008, 130 (2), 406-407.

(45) Del Regno, A.; Gonciaruk, A.; Leay, L.; Carta, M.; Croad, M.; Malpass-Evans, R.; McKeown, N. B.; Siperstein, F. R. Polymers of Intrinsic Microporosity Containing Tröger Base for $\mathrm{CO} 2$ Capture. Ind. Eng. Chem. Res. 2013, 52 (47), 16939-16950.

(46) Montagnaro, F.; Silvestre-Albero, A.; Silvestre-Albero, J.; Rodríguez-Reinoso, F.; Erto, A.; Lancia, A.; Balsamo, M. Postcombustion $\mathrm{CO} 2$ adsorption on activated carbons with different textural properties. Microporous Mesoporous Mater. 2015, 209, 157164 .

(47) Arena, F.; Italiano, G.; Barbera, K.; Bordiga, S.; Bonura, G.; Spadaro, L.; Frusteri, F. Solid-state interactions, adsorption sites and functionality of $\mathrm{Cu}-\mathrm{ZnO} / \mathrm{ZrO} 2$ catalysts in the $\mathrm{CO} 2$ hydrogenation to CH3OH. Appl. Catal., A 2008, 350 (1), 16-23.

(48) Yang, S.; Sun, J.; Ramirez-Cuesta, A. J.; Callear, S. K.; David, W. I. F.; Anderson, D. P.; Newby, R.; Blake, A. J.; Parker, J. E.; Tang, C. C.; Schröder, M. Selectivity and direct visualization of carbon dioxide and sulfur dioxide in a decorated porous host. Nat. Chem. 2012, 4 (11), 887-894.

(49) Wang, H.; Qu, Z. G.; Zhang, W.; Chang, Y. X.; He, Y. L. Experimental and numerical study of $\mathrm{CO} 2$ adsorption on $\mathrm{Ni} / \mathrm{DOBDC}$ metal-organic framework. Appl. Therm. Eng. 2014, 73 (2), 1501-1509.

(50) Liu, Y.; Wilcox, J. Effects of Surface Heterogeneity on the Adsorption of $\mathrm{CO} 2$ in Microporous Carbons. Environ. Sci. Technol. 2012, 46 (3), 1940-1947.

(51) Pan, Y.-x.; Liu, C.-j.; Mei, D.; Ge, Q. Effects of Hydration and Oxygen Vacancy on $\mathrm{CO} 2$ Adsorption and Activation on $\beta$ Ga2O3(100). Langmuir 2010, 26 (8), 5551-5558.

(52) Plaza, M. G.; Pevida, C.; Arenillas, A.; Rubiera, F.; Pis, J. J. CO2 capture by adsorption with nitrogen enriched carbons. Fuel 2007, 86 (14), 2204-2212.
(53) Pan, H.; Ritter, J. A.; Balbuena, P. B. Examination of the Approximations Used in Determining the Isosteric Heat of Adsorption from the Clausius-Clapeyron Equation. Langmuir 1998, 14 (21), 6323-6327.

(54) Krungleviciute, V.; Migone, A. D.; Yudasaka, M.; Iijima, S. CO2 Adsorption on Dahlia-Like Carbon Nanohorns: Isosteric Heat and Surface Area Measurements. J. Phys. Chem. C 2012, 116 (1), 306-310.

(55) Esteves, I. A. A. C.; Lopes, M. S. S.; Nunes, P. M. C.; Mota, J. P. B. Adsorption of natural gas and biogas components on activated carbon. Sep. Purif. Technol. 2008, 62 (2), 281-296.

(56) Demessence, A.; D’Alessandro, D. M.; Foo, M. L.; Long, J. R. Strong CO2 Binding in a Water-Stable, Triazolate-Bridged MetalOrganic Framework Functionalized with Ethylenediamine. J. Am. Chem. Soc. 2009, 131 (25), 8784-8786.

(57) Dunne, J. A.; Mariwala, R.; Rao, M.; Sircar, S.; Gorte, R. J.; Myers, A. L. Calorimetric Heats of Adsorption and Adsorption Isotherms. 1. $\mathrm{O} 2, \mathrm{~N} 2, \mathrm{Ar}, \mathrm{CO} 2, \mathrm{CH} 4, \mathrm{C} 2 \mathrm{H} 6$, and $\mathrm{SF} 6$ on Silicalite. Langmuir 1996, 12 (24), 5888-5895.

(58) Reich, T.; El-Kaderi, H. Impact of tailored chemical and textural properties on the performance of nanoporous borazine-linked polymers in small gas uptake and selective binding. J. Nanopart. Res. 2013, 15, 1368.

(59) Awadallah-F, A.; Al-Muhtaseb, S. Carbon dioxide sequestration and methane removal from exhaust gases using resorcinol-formaldehyde activated carbon xerogel. Adsorption 2013, 19 (5), 967-977.

(60) Aroonwilas, A.; Tontiwachwuthikul, P. Mass Transfer Coefficients and Correlation for $\mathrm{CO} 2$ Absorption into 2-Amino-2methyl-1-propanol (AMP) Using Structured Packing. Ind. Eng. Chem. Res. 1998, 37 (2), 569-575.

(61) Bao, Z.; Yu, L.; Ren, Q.; Lu, X.; Deng, S. Adsorption of CO2 and $\mathrm{CH} 4$ on a magnesium-based metal organic framework. J. Colloid Interface Sci. 2011, 353 (2), 549-556.

(62) Yim, W.-L.; Byl, O.; Yates, J. T.; Johnson, J. K. Vibrational behavior of adsorbed $\mathrm{CO} 2$ on single-walled carbon nanotubes. J. Chem. Phys. 2004, 120 (11), 5377-5386.

(63) Mishra, A. K.; Ramaprabhu, S. Study of $\mathrm{CO}_{2}$ Adsorption in Low Cost Graphite Nanoplatelets. Int. J. Chem. Eng. Appl. 2010, 1 (3), 266.

(64) Köck, E.-M.; Kogler, M.; Bielz, T.; Klötzer, B.; Penner, S. In Situ FT-IR Spectroscopic Study of CO2 and CO Adsorption on Y2O3, ZrO2, and Yttria-Stabilized ZrO2. J. Phys. Chem. C 2013, 117 (34), $17666-17673$. 